\title{
NREL Solar Radiation Resource Assessment Project: Status and Outlook
}

\section{FY 1992 Annual Progress Report}

D. Renné, E. Maxwell, T. Stoffel, B. Marion, M. Rymes, S. Wilcox, D. Myers, C. Riordan, E. Hammond, and $\mathrm{T}$. Ismailidis

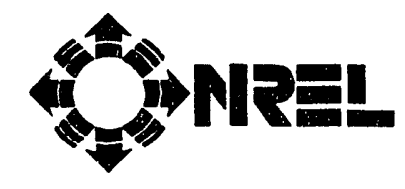

National Renewable Energy Lat oratory (formerly the Solar Energy Rese urch Institute) 1617 Cole Boulevard Golden, Colorado 80401-3393

Operated by the Midwest Research Institute for the U.S. Department of Energy under Contract No. DE-AC02-83CH10093

Prepared under Task No. RA310101 June 1993 


\section{NOTICE}

NOTICE: This report was prepared as an account of work sponsored by an agency of the United States government. Neither the Unitecl States government nor any agency thereof, nor any of their employees, makes any warranty, express or implied, or assumes any legal liability or responsibility for the accuracy. completeness, or usefulness of any information, apparatus, product, or process disclosed, or represents that its use would not infringe privately owned rights. Reference herein to any specific commercial product, process, or service by trade name, trademark, manufacturer, or othenwise does not necessarily cons situte or imply its endorsement, recommendation, or favoring by the United States government or any agency thereof. The views ancl opinions of authors expr zssed herein do not necessarily state or reflect those of the United States government or any agency thereof.

\section{Printed in the United States of America \\ Available from:}

National Technical Information Service

U.S. Department of Commerce

$$
5285 \text { Port Royal Road }
$$

Springtield, VA 22161

Price: Microfiche A01

Printed Copy AO4

Codes are used for pricing all publications. The code is determined by the number of pages in the publication. Information pertaining to the pricing codes can be found in the current issue of the following publications which are generally available in most libraries: Energy Research Abstracts (ERA); Govemment Reports Announcements and Index (GRA and I); Scientific and Technical Abstract Reports (STAR); and publication NTIS-PR-360 available from NTIS at the above address. 


\section{Preface}

This annual report summarizes the activities and accomplishments of the Solar Radiation Resource Assessment Project (SRRAP) during fiscal year 1992 (1 October 1991 to 30 September 1992).

Managed by the Analytic Studies Division of the National Renewable Energy Laboratory (NREL), SRRAP is the major activity of the Department of Energy's (DOE's) Resource Assessment Program. Since the mid-1980s, SRRAP has been funded and monitored out of the Photovoltaics Branch of DOE's Office of Conservation and Renewable Energy.

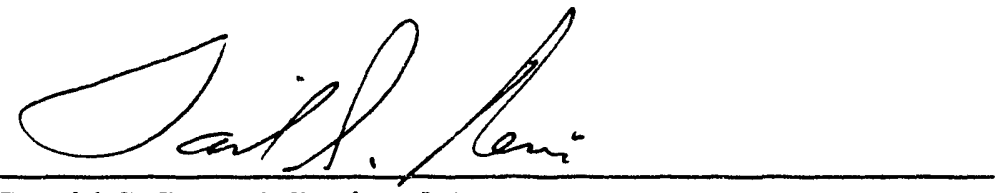

David S. Renné, Project Manager

Solar Radiation Resource Assessment Project

Approved for the

NATIONAL RENEWABLE ENERGY LABORATORY

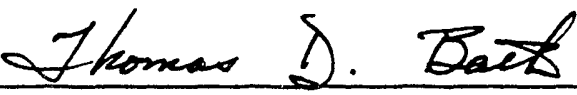

Thomas D. Bath, Director

Analytic Studies Division 


\section{Table of Contents}

$\underline{\text { Page }}$

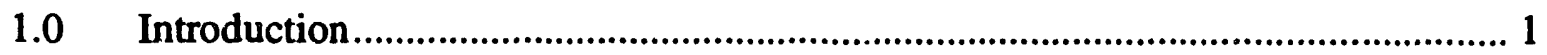

2.0 Solar Radiation Resource Assessment Project: Objectives and Scope.....................2

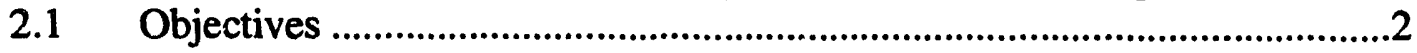

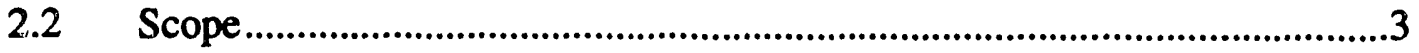

2.2.1 Continuation of a U.S. Solar Radiation Measurement

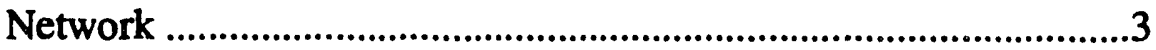

2.2.2 Solar Radiation Research and Products .............................................4

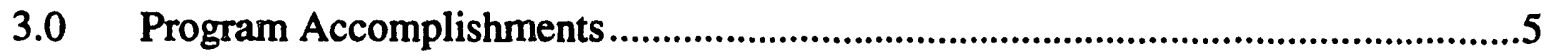

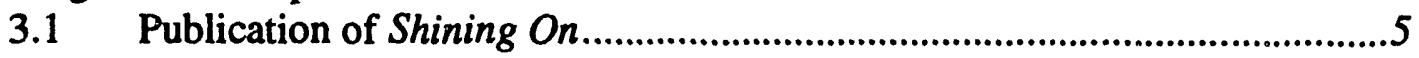

3.2 Solar Radiation Measurement Activities at the HBCUs..............................5

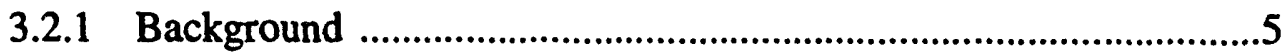

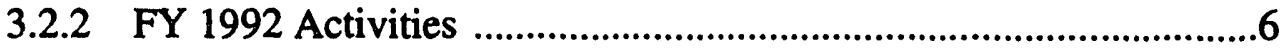

3.2.3 Data Processing .................................................................10

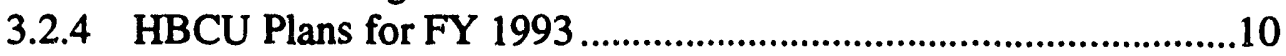

3.3 Solar Radiation Network Activities .......................................................10

3.3.1 Collaboration with the National Oceanic and Atmospheric Administration ...........................................................................10

3.3.2 Coordination with Educational Institutions and Other

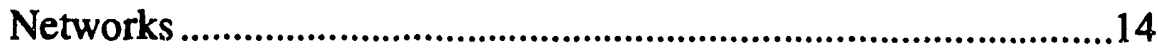

3.4 Solar Radiation Research Laboratory Activities.......................................15

3.4.1 Research Data Base ..............................................................15

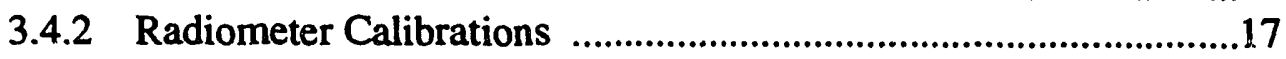

3.4.3 Research Support .................................................................18

3.4.4 FY 1993 Plans for SRRL .........................................................19

3.5 American Society of Heating, Refrigerating, and Air-Conditioning

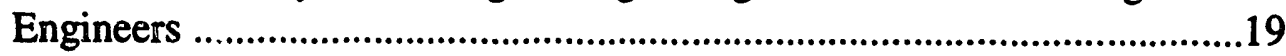

3.6 Meeting of the American Solar Energy Society .....................................19

3.7 Other Symposia and Reporting Activities ...............................................20

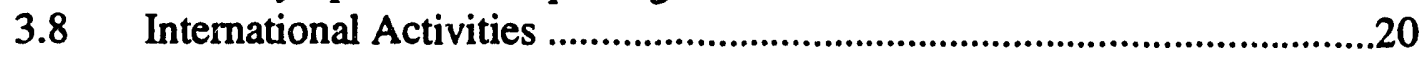

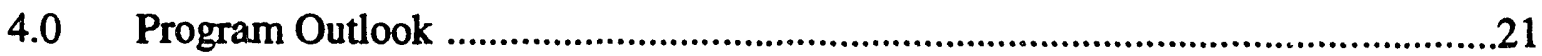

5.0 The New 1961-1990 National Solar Radiation Data Base:

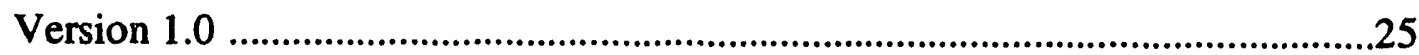

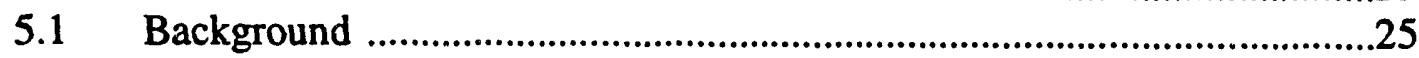

5.1.1 Rationale for Replacing the SOLMET/ERSATZ Data Base ........25

5.1.2 An Overview of the National Solar Radiation Data Base Project 


\section{Table of Contents (Concluded)}

Page

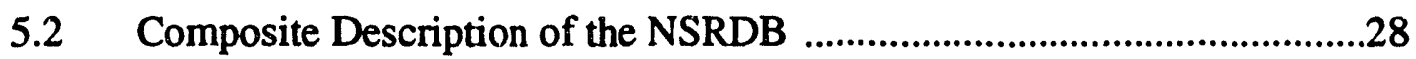

5.3 Sources of Solar Radiation and Meteorological Data .................................30

5.3.1 Meteorological Data ........................................................................30

5.3.2 Precipitable Water .......................................................................33

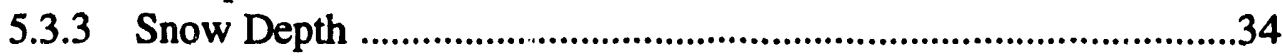

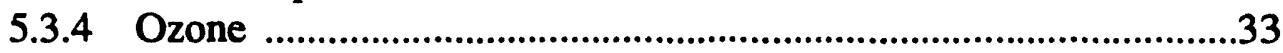

5.3.5 Filling Gaps in the Meteorological Data .......................................34

5.3.6 Deriving Precipitable Water Data ...................................................35

5.3.7 Deriving Broadband Aerosol Optical Depth ....................................35

5.4 METSTAT-A Model for Estimating Solar Radiation ............................37

5.5 Synthetic Calibration (SYNCAL) Procedures .............................................38

5.6 Comparison of the NSRDB with SOLMET/ERSATZ ...........................40

5.7 Data Base Products ..............................................................................41

5.7.1 Hourly Data ...............................................................................

5.7.2 Statistical Summaries.............................................................. 41

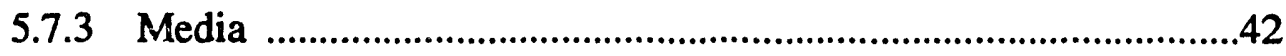

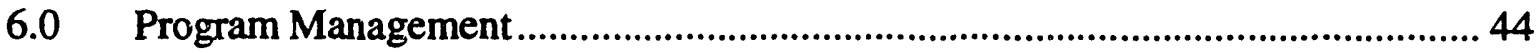

6.1 Program Reviews .............................................................................44

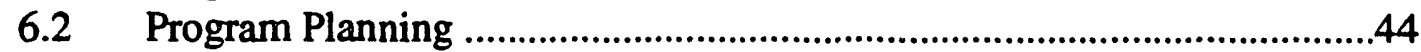

6.3 Support of DOE's Small Business Innovative Research Program ...........45

6.4 Liaison with the International Daylight Monitoring Program .................. 45

6.5 Preparations for Seminar: Recent Advances in Solar Radiation Resource Assessment ...............................................................................45

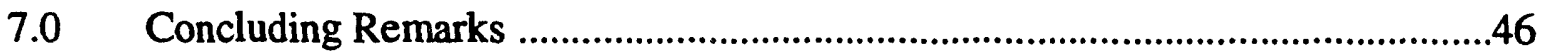

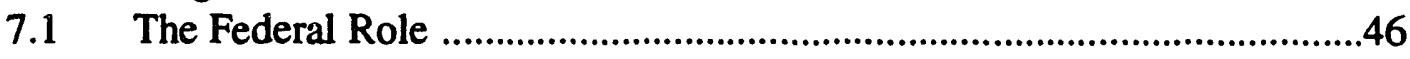

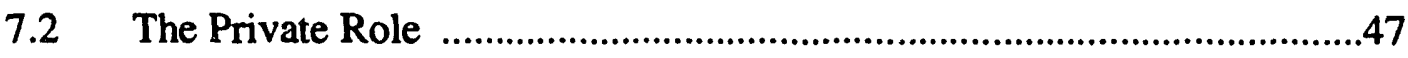

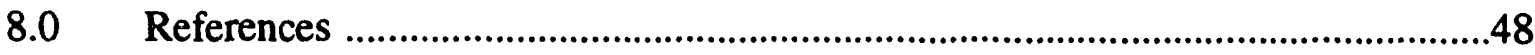

Appendix A: FY 1992 Publications by the Solar Radiation Resource Assessment Project

Appendix B: Detailed Descriptions of the METSTAT Model and the SYNCAL

Procedures Used in the NSRDB 


\section{List of Figures}

3-1. HBCU and SOLRAD monitoring stations in the southeastern United States

3-2. Sample monthly report of HBCU measurements at Bluefield State College

3-3. Monthly solar radiation data summaries for each of the six HBCU stations for FY 1992

3-4. Monthly mean daily total radiation measured by the SRRL/BMS during FY 1992

4-1. Management plan for SRRAP's FY 1993 work breakdown structure

4-2. Mean annual global horizontal solar radiation, $\mathrm{kWh} / \mathrm{m}^{2} / \mathrm{day}$, based on interpolation of the NSRDB. Cross-hatching represents areas of least certainty in analysis.

5.1 Locations of all Primary and Secondary stations used in the NSRDB 31

5-2. Monthly means and standard deviations of broadband aerosol optical depth for all years versus day of the year for Albuquerque. A sine function is fitted to the data.

5-3. Monthly mean differences between calculated aerosol optical depth for individual days and daily values derived from the seasonal sine function for Albuquerque. The solid curve was obtained by smoothing lidar measurements at Mauna Loa, Hawaii, and from SAGE II satellite measurements; it represents stratospheric aerosol optical depth.

5-4. Block diagram of the meteorological-statistical (METSTAT) model developed for estimating solar radiation from meteorological parameters 


\section{List of Tables}

Page

3-1. HBCU Network Stations and Measurements Status...........................................

3-2. HBCU Network Data Recovery FY 1992 .....................................................11

3-3. SRRL Baseline Monitoring System Data Channels .......................................16

5-1. Solar Radiation and Meteorological Elements in the NSRDB ..........................29

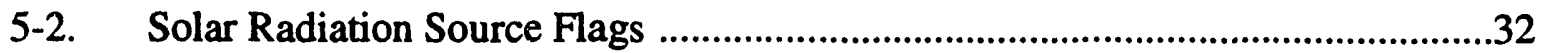

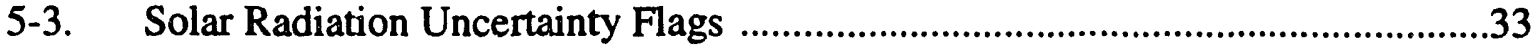




\subsection{Introduction}

Our accomplishments in FY 1992 will make the year 1993 a major transition year for the Solar Radiation Resource Assessment Project (SRRAP). The new National Solar Radiation Data Base (NSRDB), which replaces the SOLMET/ERSATZ data base, was completed in August 1992. The NSRDB is important to a variety of resource assessment activities that will be initiated in FY 1993. These include development of up-to-date maps of national solar resources, using computerized geographic-based systems; development of revised typical meteorological year and design year data sets; and publication of the models and the results of research that went into developing the data base. The SRRAP also continues to monitor solar resources at six Historically Black Colleges and Universities (HBCUs) and at NREL's Solar Radiation Research Laboratory (SRRL), and provides documents and products that assists industry in deploying solar energy systems and assist analysts in evaluating projects. All of these activities are designed to fulfill the SRRAP mission, which is to provide objective, high-quality, and relevant information and data to users and planners of solar energy technologies so that timely and informed decisions concerning the application of those technologies can be made.

Section 2.0 of this report provides the objectives of SRRAP and outlines the scope of activities in which we have been engaged over the past several years. Section 3.0 describes our major accomplishments and our measurement programs. Our measurement programs include activities at the six-station HBCU network and our activities with other networks, including the National Oceanic and Atmospheric Administration's SOLRAD (SOLar RADiation) network. In Section 4.0, we discuss the planned activities for SRRAP during FY 1993 and beyond; and Section 5.0 provides detailed information on the development of the NSRDB and includes a description of the final contents of the data base. In Section 6.0, we summarize key project management activities related to SRRAP.

We conclude our FY 1992 annual report with Section 7.0 by discussing the federal versus the private role in renewable energy resource assessment activities. Section 8.0 contains the references cited in this report, and Appendix A lists the publications produced by the SRRAP staff during FY 1992. Appendix B includes detailed descriptions of the METSTAT (METeorologicalSTATistical) model and the SYNCAL (SYNthetical CALibration)procedures used in the NSRDB. 


\subsection{Solar Radiation Resource Assessment Project: Objectives and Scope}

High-quality renewable energy resource data, and the products that guide and enhance the use of these data, are critical to the viability and success of the renewable technology industry. Utilities, the federal government, and private industry will invest millions of dollars over the next few years to support demonstration projects and to commercialize grid-connected renewable energy projects. Resource information is essential to understand the economic performance of energy systems over their expected life, to compare one type of system with another at the same location, and to evaluate the possible use of hybrid systems (such as wind and solar). For these applications, a lot of money is at stake to assure that energy systems, along with their storage components, are sized properly for their particular location. For example, the architectural community allocates large sums of money on daylighting and energy efficiency designs for buildings. Generally, they must use daylighting models, which have not received extensive validation, to determine these designs because of a lack of widespread and adequate illuminance data.

Our entire National Energy Strategy is based, in part on, an accurate and credible understanding of the availability of resources for fueling various technologies. Proponents of the industry require accurate resource information to make credible claims about the performance and cost of the technologies. In addition, all of the end uses of resource information highly depend on the research community to produce the high-quality, accurate data that go into planning for the deployment of renewable technologies and comparing alternative technological approaches. The research community has the responsibility to package the information in a way that can be used efficiently and reliably by government and industry planners.

All of this shows that there is a high value in quality, accurate data. The mission of the Solar Radiation Resource Assessment Project (SRRAP) is to provide these data to the solar energy constituency and to foster the proper use of these data by developing relevant products.

\subsection{Objectives}

To fulfill its mission, the SRRAP has adopted a strategy to focus activities in several areas. This strategy includes the following objectives:

1. Archive and disseminate solar radiation resource products based on historical data.

2. Encourage the continuation and improvement of resource data collection and characterization on a national scale.

3. Conduct research aimed at shortening project evaluation time and reducing resource related uncertainties. 
4. Develop solar radiation rescurce products that transfer our research results to industry so that resource-related barriers to deployment are minimized.

5. Provide constituents with effective responses to resource-related issues.

\subsection{Scope}

Over the past three years (FY 1990 to FY 1992), the SRRAP's major activity has been the development of the new National Solar Radiation Data Base (NSRDB), described in detail in Section 5.0. However, the broad-based strategy, listed in Section 2.1, has kept SRRAP staff involved in other critical activities as well. Some of the key activities are summarized here.

\subsubsection{Continuation of a U.S. Solar Radiation Measurement Network}

The National Oceanic and Atmospheric Administration's (NOAA's) SOLRAD (SOLar RADiation) network, which forms the basis for both the SOLMET/ERSATZ and NSRDB, has been undergoing increasing budget riductions over the past several years as the National Weather Service (NWS), the department within NOAA that operates SOLRAD, attempts to modernize and automate its weather forecasting and observation system. Shifting budget and operational priorities away from SOLRAD and toward the improvement of short-term, mesoscale weather forecasts has decreased SOLRAD in size and performance since the mid-1980s. By the fall of 1991, senior NWS management recommended shutting down the network altogether by December 1991. However, the NOAA Office of Global Studies agreed to provide additional support to keep the network operational through FY 1992. Recently, there have been initiatives within NOAA to establish a new network that focuses mure on global climate research issues. This would give the network a more scientific focus; as a result, the network may comprise fewer stations than SOLRAD. The network would also fall under the jurisdiction of other departments within NOAA rather than NWS.

Taking the position that a national solar radiation network is critical to a growing and viable solar technology industry, NREL has been working closely with NOAA to seek ways in which operating the new or restructured network can be cost shared so that it can meet specific solar resource programmatic objectives. By the end of 1992, it appeared that a solution had been reached in which NREL, and perhaps other agencies, would play an active partnership role in a new research network, called SURFRAD, under management of NOAA's Air Resources Laboratory (ARL).

Besides this collaboration with NOAA, the SRRAP manages its own network of six HBCU stations in the southeastern United States. This activity is described in more detail in Section 3.0. Continuous measurements of total direct, global horizontal, and diffuse radiation have been made at these sites since 1985. During 1992, T. Stoffel, who manages the network for SRRAP, implemented a modernization program by installing telephone dial-up modems at some of the sites. NREL also continues measurement activities at the SRRL, on top of South Table Mountain neir Golden, Colorado. Through these programs, we are continually seeking ways to improve the eficiency and cost-effectiveness of site characterization procedures that can be adapted by industry to perform its own site measurements. 
As resources become available, we will seek ways to expand and enhance the national network. In Subsection 3.2 and in Section 4.0, we describe a program that will be announced formally in FY 1993 to achieve this through cost-sharing activities between NREL and cther network operators.

\subsubsection{Solar Radiation Research and Products}

A considerable amount of research went into the development of the NSRDB. Much of this research is directly applicable to the solar industry. For example, we can model solar resources with a reasonable degree of certainty, using standard NWS meteorological observations when no solar measurements are available. We have developed methods for rehabilitating historical radiation data that were collected without the benefit of a rigorous calibration program or when instrument exposures or characteristics changed with time. We also developed data quality assessment procedures that can be implemented either on mainframe computers or a personal computer. Development of the NSRDB also resulted in improved methods for characterizing the spatial and temporal distribution of atmospheric aerosol optical depth and precipitable water. Results of these studies are forthcoming in NREL technical reports and journal articles in 1993.

SRRAP staff members produced several key reports and conducted a broad array of technical liaison and technology transfer activities over the past year. We describe these in greater detail in Section 3.0. As an example, B. Marion prepared a solar radiation primer titled Shining On (NREL 1992a). This document provides basic information on how solar radiation data are obtained and how they are used. Nearly 1700 copies have been distributed since its publication in May 1992.

Besides these activites, SRRAP staff members have been involved in a number of outreach and project management responsibilities during FY 1992. We will describe all of these in greater detail as we present the FY 1992 achievements of SRRAP. 


\subsection{Program Accomplishments.}

Besides the completion of the NSRDB, which we describe in Section 5.0, SRRAP accomplishments include a wide range of publications and participation in professional organizations. The following represent some key examples for FY 1992.

\subsection{Publication of Shining On}

In May 1992, we published a 28-page two-color document entitled Shining On: A Primer on Solar Radiation Data (NREL 1992a). This document uses a friendly question-and-answer format and numerous illustrations to describe solar radiation data and how they can be used. Shining On explains what solar radiation data are, why solar radiation data are needed, what influences the amount of solar radiation, what parts of solar radiation are measured, how solar radiation data are used, where solar radiation data may be obtained, how accurate solar radiation data needs to be, and how we will meet our solar radiation data needs.

Shining $O n$ is an informative document written for solar engineers and designers; solar industries; utilities and companies who may be considering installing solar systems; and managers and individuals at DOE, national laboratories, universities, and state and federal government involved in solar radiation research and technology deplo;'ment. During the development of Shining On, we enlisted support from Sandia, the Electric Power Research Institute (EPRI), and the American Society of Heating, Refrigerating, and Air-Conditioning Engineers (ASHRAE) in reviewing the document and contributing to its subject matter in the form of quotations. The quotations add depth to the document and help the reader to identify how solar radiation data are applicable and important to his or her particular application.

Shining On has been well received by both DOE and industry. Sandia requested 200 copies for distributing to their clients, and EPRI and others are using Shining On for workshops pertaining to various solar energy technologies. Demand is high enough that we plan to reprint the document in early 1993 when the initial printing of 2000 copies is depleted.

\subsection{Solar Radiation Measurement Activities at the HBCUs}

NREL continues to fund and oversee the HBCU Solar Radiation Measurement Network, which has been in operation at six locations in the southeastern United States since 1985. Several major accomplishments were realized during FY 1992, significantly improving the quality of research data available from this project.

\subsubsection{Background}

The objectives of the network continue to be realized:

- To significantly improve the assessment of solar radiation resources in the Southeast. 
- To encourage the development of academic and research programs in solar energy at HBCUs.

- To encourage the distribution of solar radiation resource information and the development of solar energy applications in the Southeast.

The HBCU network improves the spatial distribution of solar radiation measurements in the Southeast by augmenting the NOAA SOLRAD network, as shown in Figure 3-1. This significantly enhances our ability to perform solar radiation resource assessments for this region of the United States.

Each station is equipped with a thermopile-type pyranometer for measuring global horizontal solar radiation, a shadowband stand with another pyranometer for measuring the diffuse horizontal solar radiation, and a battery-powered microprocessor-based data acquisition system for recording 5-minute averages of 10-second samples. Three of the stations also have pyrheliometers mounted in automatic sun-following trackers powered by photovoltaic/battery systems for measuring the direct normal solar radiation, as shown in Table 3-1. The radiometers and data logging equipnent are scheduled for annual recalibration by the NREL Metrology Laboratory.

Daily maintenance activities at each station are recorded by the observer/technician on a standard form. Completed forms are sent to NREL with the corresponding data records as an aid for data processing. High-resolution (5-minute) solar irradiance data from each station are recorded on cassette tapes and printer listings; these data are mailed monthly and bi-monthly to NREL for processing. The raw measurements are transferred from the cassette tapes to digital files in NREL's Standard Broadband Format (SBF), which includes data quality assurance test results (SERI 1988). Monthly reports of hourly and daily statistics are produced before the data are archived (see Figure 3-2). All raw and processed data files are stored at NREL. The raw and SBF files also are sent to an off-site archival location for added protection.

\subsubsection{FY 1992 Activities}

Although data recovery has exceeded $95 \%$ for the period 1985 to 1990 , recent experience indicated the need for more timely access to the data by eliminating the cassette tape data transfer via mail. After equipment testing and evaluation at NREL's Solar Padiation Research Laboratory (SRRL), telephone modems were purchased for each station to provide daily access to the network data collection.

Prior to 1991, we maintained a set of six spare data loggers and three radiometers for rapid deployment to the network sites. Our recalibration efforts were limited to a round-robin approach using an exchange of the three radiometers, site by site; the set was returned to NREL and recalibrated at SRRL before being sent to the next HECU network station. Previous attempts to accomplish the installation of recalibrated equipment by the station staff, guided by detailed instructions and telephone support from NREL, have shown mixed results; data losses have ranged from 1 hour to 1 month, depending on the site. 


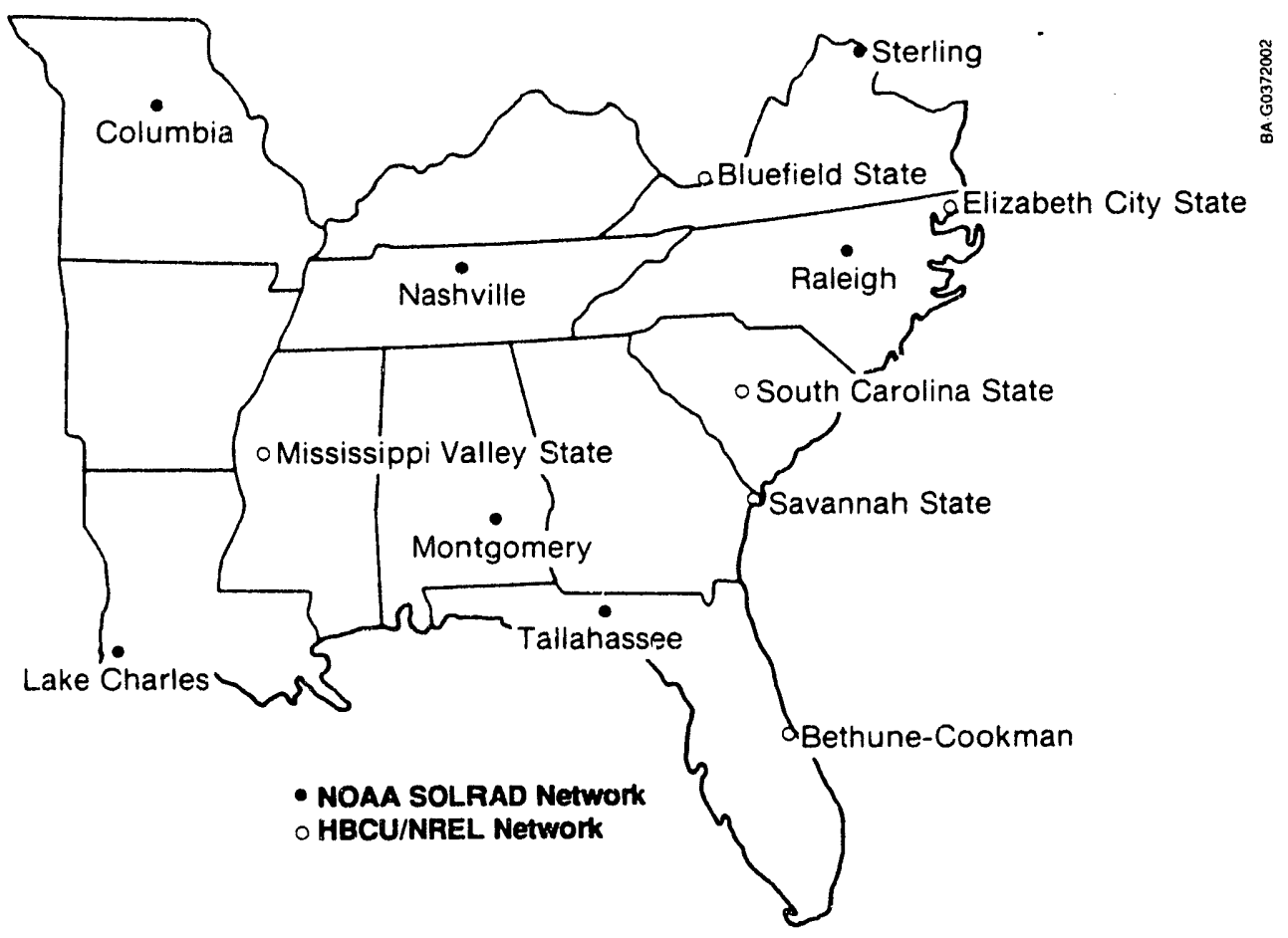

Figure 3-1. HBCU and SOLRAD monitoring stations in the southeastern United States

Table 3-1. HBCU Network Stations and Measurements Status

\begin{tabular}{|l|c|c|c|}
\hline \multicolumn{1}{|c|}{ Station Name } & \multicolumn{2}{c|}{ Measured Solar Irradiance } \\
\hline & Global & Diffuse & Direct \\
\hline \hline $\begin{array}{l}\text { Bethune-Cookman College } \\
\text { Daytona Beach, Florida }\end{array}$ & $\mathrm{X}$ & $\mathrm{X}$ & \\
\hline $\begin{array}{l}\text { Bluefield State College } \\
\text { Bluefield, West Virginia }\end{array}$ & $\mathrm{X}$ & $\mathrm{X}$ & $\mathrm{X}$ \\
\hline $\begin{array}{l}\text { Elizabeth City State University } \\
\text { Elizabeth City, North Carolina }\end{array}$ & $\mathrm{X}$ & $\mathrm{X}$ & $\mathrm{X}$ \\
\hline $\begin{array}{l}\text { Mississippi Valley State University } \\
\text { Itta Bena, Mississippi }\end{array}$ & $\mathrm{X}$ & $\mathrm{X}$ & $\mathrm{X}$ \\
\hline $\begin{array}{l}\text { South Carolina State University } \\
\text { Orangeburg, South Carolina }\end{array}$ & $\mathrm{X}$ & $\mathrm{X}$ & \\
\hline $\begin{array}{l}\text { Savannah State College } \\
\text { Savannah, Georgia }\end{array}$ & $\mathrm{X}$ & $\mathrm{X}$ & \\
\hline
\end{tabular}




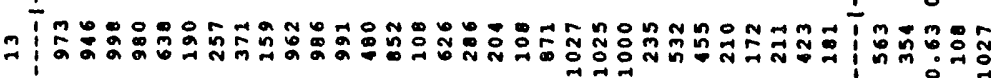

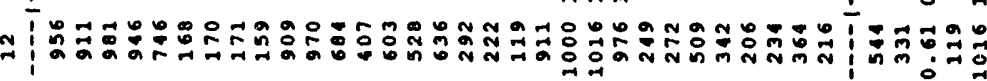

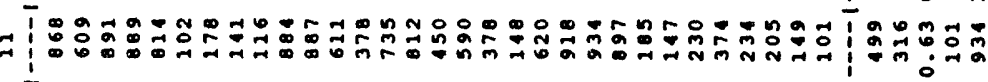

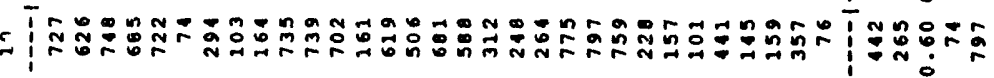

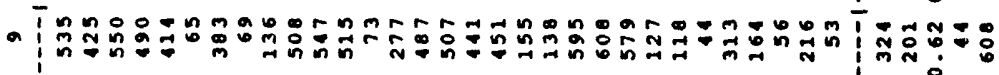

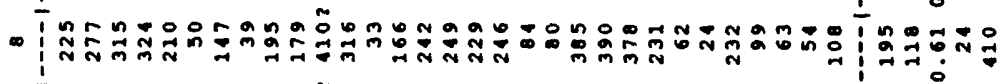

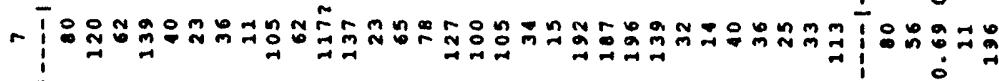

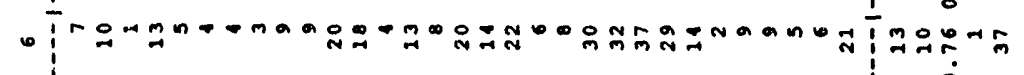
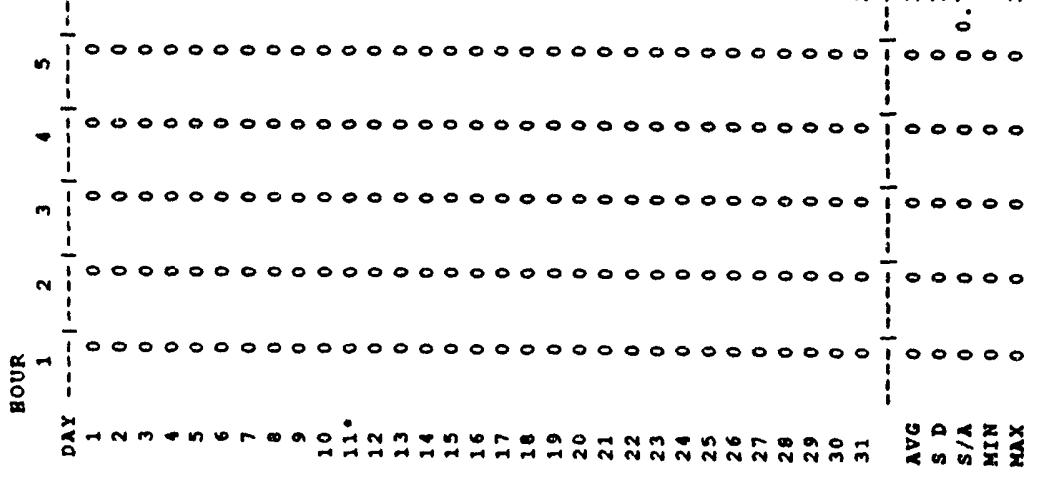
When all the equipment was due for recalibration and additional "spare" radiometers were identified, we sent two NREL technical staff members on a three-week tour of the network in Jure 1992. They installed recalibrated instruments and equipment upgrades. The replacement data loggers and radiometers were recalibrated by NREL's Metrology Laboratory before the site visits. This marked the first time each site had been visited since the original site visits made by $\mathrm{E}$. Maxweil at the beginning of the project in 1985. The purpose of the visit was to perform the following quality assurance operations:

1. Examine and note the condition of existing equipment.

2. Exchange existing radiometers with units newly calibrated at SRRL.

3. Replace existing (weathered) signal cables connecting instruments on the roof to the data logger.

4. Upgrade automatic solar trackers to PV-powered systems at Bluefield State College and Elizabeth City State University.

5. Add the capability of measuring the direct normal solar irradiance at Mississippi Valley State University by installing a pyrheliometer and PV-powered automatic solar tracker.

6. Check shadowband stand installations and adjust alignment as needed.

7. Reorient the diffuse pyranometer at all sites with the signal cable connector oriented toward the north.

8. Exchange existing data logger with a newly calibrated unit.

9. Install modems for telecommunication in the data logger.

10. Return to NREL existing instruments that were due for recalibration.

11. Review all maintenance and standard operating procedures with the principal investigators and student technicians.

12. Perform a property inventory audit of all government furnished equipment.

13. Document installation using 35-mm print/slide and VHS video (station staff, radiometers, data acquisition system, campus building, and local horizon/fields of view).

The NREL team worked effectively to accomplish these basic tasks. In addition, the visits proved to be very successful by reinforcing NREL's interest in continuing a well-run monitoring network. The NREL staff were welcomed at each station and provided with everything needed to accomplish their tasks, including the direct involvement of the principal investigator. 
Although successfully tested at NREL and at each station during the visit, we were unable to use the telephone modems for acquiring the data from all but one of the HBCU stations after returning to NREL. The probable cause has been identified as the combination of noise on the longdistance telephone connections and the inadequate telecommunications capabilities of the data loggers under these conditions.

\subsubsection{Data Processing}

Average network data recovery during FY 1992 was 93\%, and nearly $100 \%$ of the measurements passed NREL quality assurance tests, as shown in Table 3-2. All missing data are the result of hardware problems and/or failures beyond the control of the station staff. The high quality of available data is the direct result of the excellent maintenance and operation of each station by the HBCU principal investigator and his or her staff. All measurements collected during the FY 1992 have been processed, as described previously. A summary of the network's solar radiation measurements during FY 1992 is shown in Figure 3-3.

\subsubsection{HBCU Plans for FY 1993}

The subcontracts with each of the six HBCU stations will be renewed for calendar year 1993. Upgraded data loggers have been ordered to replace the existing units and to allow for error-free data recovery from NREL using automated telephone modem dial-up. Already in service at Bluefield State College, this dial-up system will reduce the anount of processing required at NREL by eliminating the cassette tape data transfers and will provide real-time access to each of the stations data collection. The video tape images collected during the first network tour will be edited and sent to each of the principal investigators. This will be the first opportunity for them to "meet" each other and observe the station layout and operations of the other team members.

\subsection{Solar Radiation Network Activities}

SRRAP continues to interact with other network activities having the goal of assuring that highquality measurements continue in the United States, and that access to this information is widely available. The following are two key examples of this interaction.

\subsubsection{Collaboration with the National Oceanic and Atmospheric Administration}

Collaboration with NOAA and, in particular, representatives of the NWS to explore options for continuing the SOLRAD network, perhaps under some form of multiagency support, has been a continuing SRRAP activity over the past few years. In February 1992, when SOLRAD was on the verge of extinction because of a lack of funding, D. Renné participated in a multiagency meeting in Washington, D.C., to discuss this issue. This particular meeting was led by NOAAs Office of Global Change Research, which recognizes the need for continuous, long-term solar radiation measurements as part of an effort to monitor climate change in the United States. Representatives from a wide spectrum of the scientific community and government agencies participated and presented views on the need for these data for a variety of programs. The outcome of the meeting was positive, producing both short-term and long-term actions to continue and redefine solar radiation measurements in the United States. The short-term action 
Table 3-2. HBCU Network Data Recovery FY 1992

\begin{tabular}{|c|c|c|c|c|c|c|}
\hline \multirow[t]{2}{*}{$\begin{array}{c}\text { Month } \\
\text { Year }\end{array}$} & \multicolumn{6}{|c|}{ Stations } \\
\hline & $\mathrm{BC}$ & BS & $\mathrm{EC}$ & MV & SC & SS \\
\hline $\begin{array}{l}\text { Oct. } \\
1991\end{array}$ & $\begin{array}{l}0-M \\
0-Q\end{array}$ & $\begin{array}{l}0-M \\
0-Q\end{array}$ & $\begin{array}{l}0-M \\
0-Q\end{array}$ & $\begin{array}{l}0-M \\
0-Q\end{array}$ & $\begin{array}{l}0-M \\
0-Q\end{array}$ & $\begin{array}{l}0-M \\
0-Q\end{array}$ \\
\hline $\begin{array}{l}\text { Nov. } \\
1991\end{array}$ & $\begin{array}{l}0-M \\
0-Q\end{array}$ & $\begin{array}{l}0-M \\
0-Q\end{array}$ & $\begin{array}{l}0-M \\
0-Q\end{array}$ & $\begin{array}{l}0-M \\
0-Q\end{array}$ & $\begin{array}{l}0-M \\
0-Q\end{array}$ & $\begin{array}{l}0-M \\
0-Q\end{array}$ \\
\hline $\begin{array}{l}\text { Dec. } \\
1991\end{array}$ & $\begin{array}{l}0-M \\
0-Q\end{array}$ & $\begin{array}{l}0-M \\
0-Q\end{array}$ & $\begin{array}{l}0-M \\
0-Q\end{array}$ & $\begin{array}{l}0-M \\
0-Q\end{array}$ & $\begin{array}{l}0-M \\
0-Q\end{array}$ & $\begin{array}{l}0-M \\
0-Q\end{array}$ \\
\hline $\begin{array}{l}\text { Jan. } \\
1992\end{array}$ & $\begin{array}{c}61-M \\
0-0\end{array}$ & $\begin{array}{l}0-M \\
0-Q\end{array}$ & $\begin{array}{l}0-M \\
0-Q\end{array}$ & $\begin{array}{l}0-M \\
0-Q\end{array}$ & $\begin{array}{l}0-M \\
0-Q\end{array}$ & $\begin{array}{l}1-M \\
0-1\end{array}$ \\
\hline $\begin{array}{l}\text { Feb. } \\
1992\end{array}$ & $\begin{array}{l}0-M \\
0-Q\end{array}$ & $\begin{array}{l}0-M \\
0-Q\end{array}$ & $\begin{array}{l}0-M \\
0-Q\end{array}$ & $\begin{array}{l}-M \\
0-Q\end{array}$ & $\begin{array}{l}0-M \\
0-Q\end{array}$ & $\begin{array}{l}0-M \\
0-Q\end{array}$ \\
\hline $\begin{array}{l}\text { Mar. } \\
1992 \\
\end{array}$ & $\begin{array}{l}0-M \\
0-Q\end{array}$ & $\begin{array}{l}0-M \\
0-Q\end{array}$ & $\begin{array}{l}0-M \\
0-Q\end{array}$ & $\begin{array}{l}0-M \\
0-Q\end{array}$ & $\begin{array}{l}0-M \\
0-Q\end{array}$ & $\begin{array}{c}22-M \\
0-Q\end{array}$ \\
\hline $\begin{array}{l}\text { Apr. } \\
1992\end{array}$ & $\begin{array}{l}0-M \\
0-Q\end{array}$ & $\begin{array}{l}0-M \\
0-Q\end{array}$ & $\begin{array}{l}0-M \\
0-Q\end{array}$ & $\begin{array}{l}0-M \\
0-Q\end{array}$ & $\begin{array}{l}0-M \\
0-Q\end{array}$ & $\begin{array}{l}3-M \\
0-Q\end{array}$ \\
\hline $\begin{array}{l}\text { May } \\
1992\end{array}$ & $\begin{array}{l}0-\mathbf{M} \\
0-Q\end{array}$ & $\begin{array}{l}0-M \\
0-Q\end{array}$ & $\begin{array}{l}0-M \\
0-Q\end{array}$ & $\begin{array}{l}0-M \\
0-Q\end{array}$ & $\begin{array}{l}0-M \\
0-Q\end{array}$ & $\begin{array}{l}0-M \\
0-Q\end{array}$ \\
\hline $\begin{array}{l}\text { June } \\
1992\end{array}$ & $\begin{array}{l}0-M \\
1-Q\end{array}$ & $\begin{array}{c}70-M \\
0-Q\end{array}$ & $\begin{array}{c}25-M \\
5-Q\end{array}$ & $\begin{array}{c}11-M \\
1-Q\end{array}$ & $\begin{array}{l}7-M \\
0-Q\end{array}$ & $\begin{array}{c}21-M \\
0-Q\end{array}$ \\
\hline $\begin{array}{l}\text { July } \\
1992\end{array}$ & $\begin{array}{c}98-M \\
0-Q\end{array}$ & $\begin{array}{l}7-M \\
1-Q\end{array}$ & $\begin{array}{l}0-M \\
0-Q\end{array}$ & $\begin{array}{c}16-M \\
0-Q\end{array}$ & $\begin{array}{l}0-M \\
0-Q\end{array}$ & $\begin{array}{c}45-M \\
0-Q\end{array}$ \\
\hline $\begin{array}{l}\text { Aug. } \\
1992\end{array}$ & $\begin{array}{c}54-M \\
0-Q\end{array}$ & $\begin{array}{l}0-M \\
1-Q\end{array}$ & $\begin{array}{c}19-M \\
0-Q\end{array}$ & $\begin{array}{l}0-M \\
0-Q\end{array}$ & $\begin{array}{l}0-M \\
0-Q\end{array}$ & $\begin{array}{l}1-M \\
0-Q\end{array}$ \\
\hline $\begin{array}{l}\text { Sept. } \\
1992\end{array}$ & $\begin{array}{l}2-M \\
0-Q\end{array}$ & $\begin{array}{c}52-\mathrm{M} \\
0-\mathrm{Q}\end{array}$ & $\begin{array}{l}0-M \\
0-Q\end{array}$ & $\begin{array}{l}9-M \\
0-Q\end{array}$ & $\begin{array}{l}0-M \\
0-Q\end{array}$ & $\begin{array}{l}0-M \\
0-Q\end{array}$ \\
\hline
\end{tabular}

$\mathrm{BC}=$ Bethune-Cookman College

BS = Bluefield State College

$\mathrm{EC}=$ Elizabeth City State University

MV = Mississippi Valley State University

SC = South Carolina State University

SS = Savannah State College

$M=$ Percentage of 5-minute data missing during the month

$\mathrm{Q}=$ Percentage of 5-minute data above $15 \%$ quality assurance threshold 

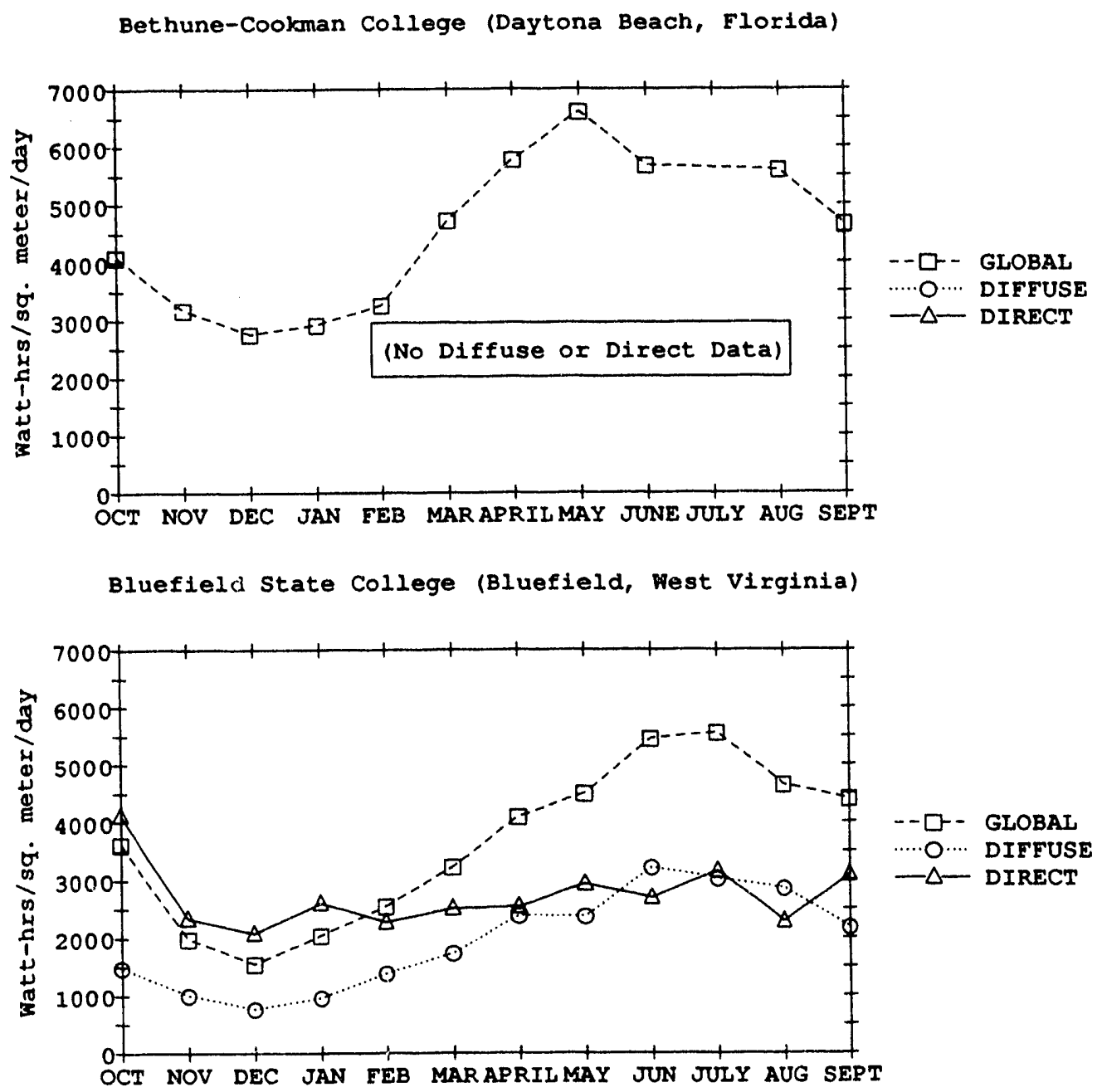

Elizabeth City State University (Elizabeth City, North Carolina)

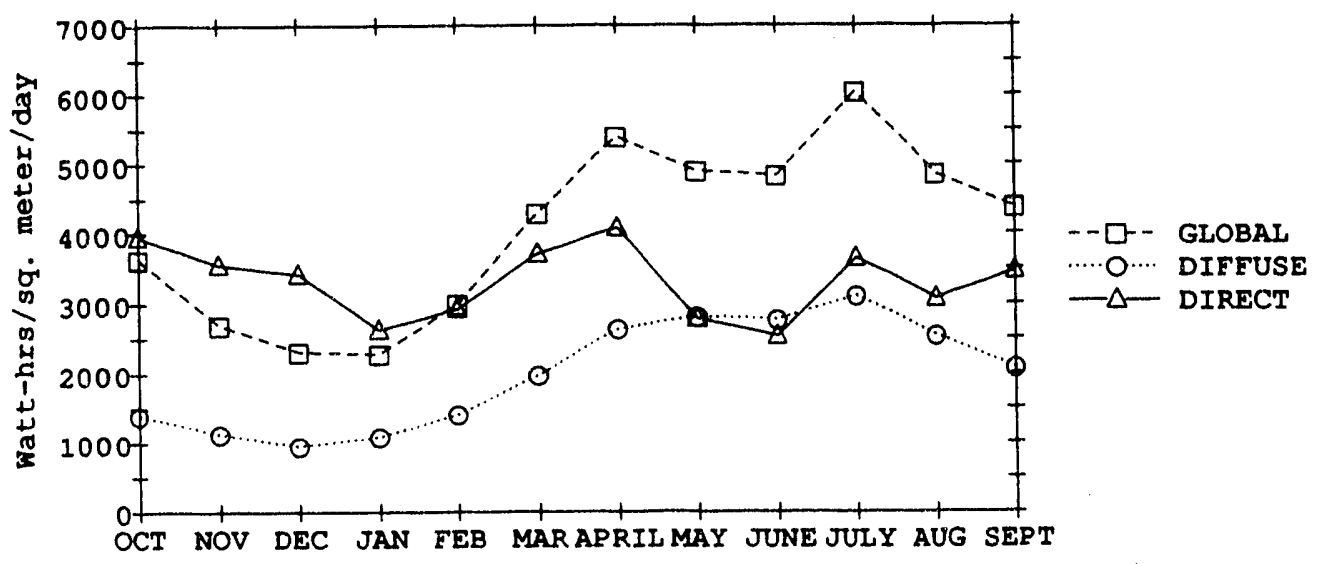

Figure 3-3. Monthly solar radiation data summaries for each of the six HBCU stations for FY 1992 (based on days with 100\% data recovery). 
Mississippi Valley State University (Itta Bena, Mississippi)

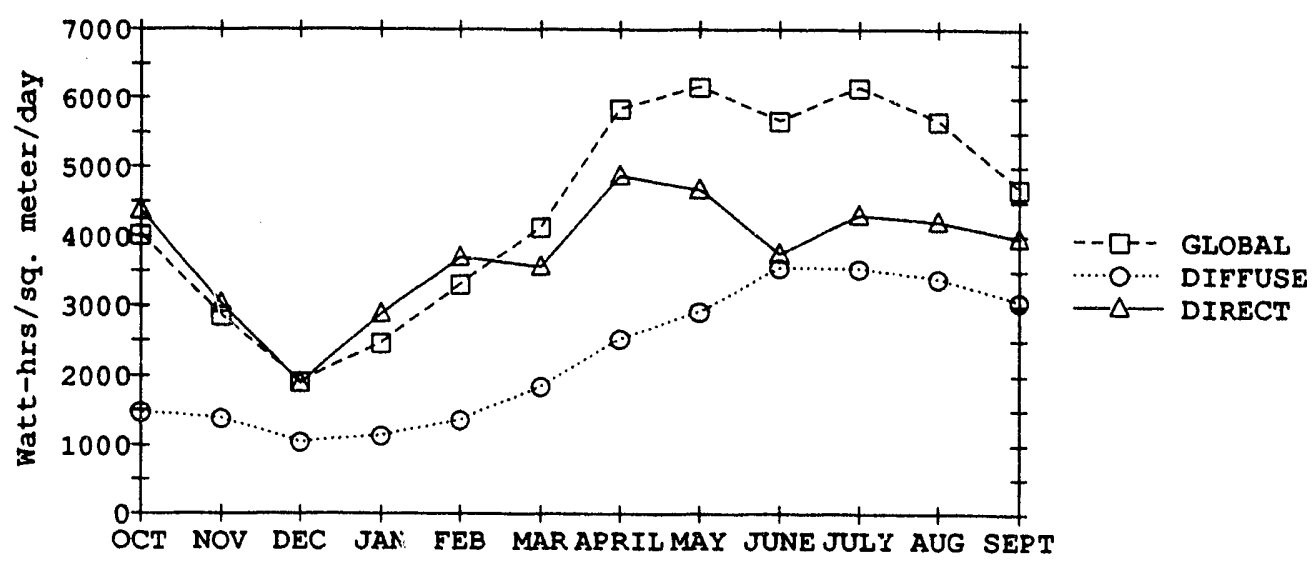

South Carolina State University (Orangeburg, South Carolina)

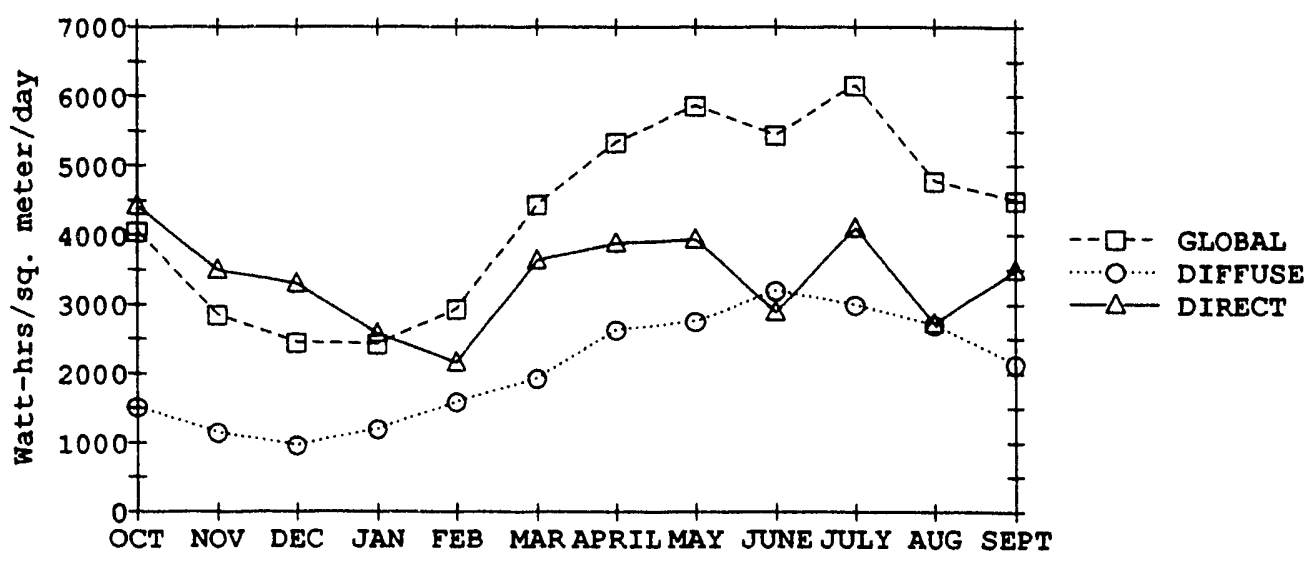

Savannah State College (Savannah, Georgia)

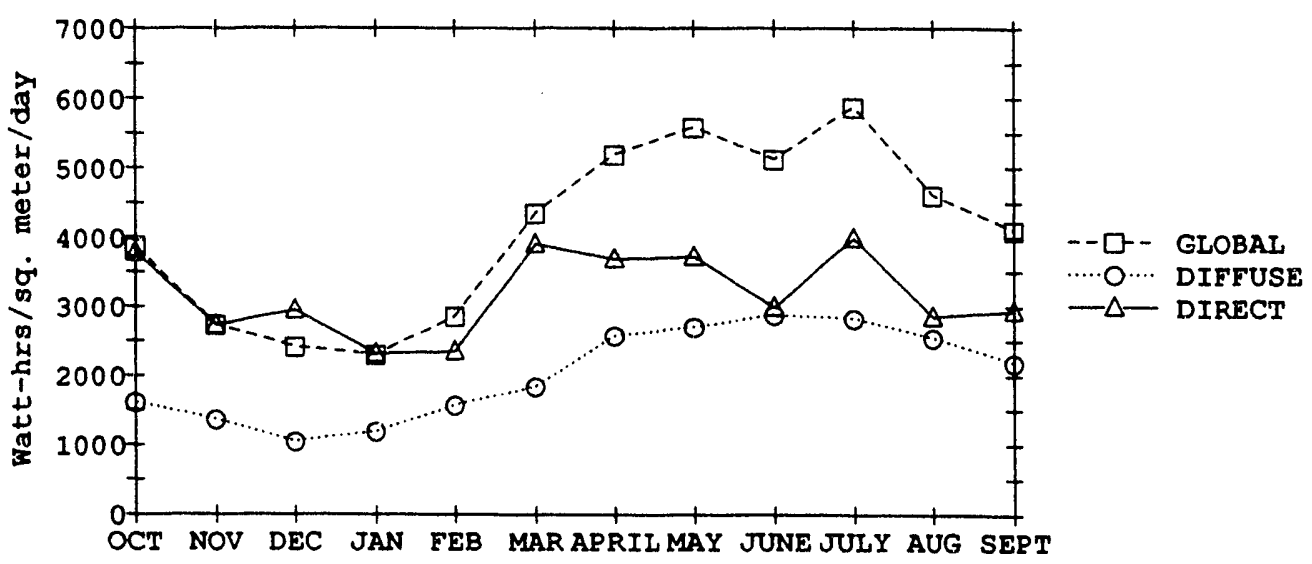

Figure 3-3. Continued 
was for the Office of Global Change to provide sufficient funding to continue SOLRAD for at least the remainder of FY 1992. Although the funding level was insufficient to calibrate and repair existing instruments, it was sufficient to assure that the network received the attention necessary to continue data collection and archiving activities.

Along with this short-term action came a request to develop a long-terna plan for a future network. NOAA's Air Resources Laboratory (ARL) has taken the lead on this activity. ARL has worked closely with NREL to define a multiagency role. By the end of FY 1992, the plan was for SOLRAD to evolve into a smaller research-grade network called SURFRAD (SURFace RADiation). The idea is for SURFRAD, which may ultimately consist of no more than 10 to 15 stations, to provide high-quality measurements of a variety of environmental parameters, including solar radiation. These data will be used to address issues such as climate change, agricultural production, and air quality. This is part of an FY 1994 "Health of the Atmosphere" initiative, which would irclude solar radiation in a nested network. This nested network would fall within the proposed AIRMN (Atmospheric Integrated Research Monitoring Network). NREL's role is evolving to provide primary calibration support for the radiometers used in SURFRAD and to assist NOAA's Atmospheric Turbulence and Diffusion Division (ATDD) in Oak Ridge, Tennessee, in data processing and archiving (ATDD will be the technical operators of the new network).

Both NOAA and NREL view SURFRAD as part of a nested network concept, consistent with earlier plans for maintaining a few high-quality stations around the United States at strategic locations, each forming the basis for a regional network of secondary and perhaps even tertiary measurement sites. In this way, dense geographic coverage can be achieved without excessive costs since the siting of the secondary and tertiary stations will be such that they can be compared with the primary, high-quality stations. Support for this nested network would come through multiagency initiatives such as the SRRAP educational initiative and other network activities described in the next sections.

\subsubsection{Coordination with Educational Institutions and Other Networks}

Besides our continuing work with the six HBCU sites in the southeastern United States, SRRAP has been engaged in discussions with the University of Oregon regarding support for the continuation of the Pacific Northwest Network, which it operates. This network is funded by the Eugene Water and Electric Board (EWEB). During FY 1992, EWEB and the University of Oregon submitted a proposal to the Bonneville Power Administration for enhancing the network activities. Included in this proposal was a provision for NREL to cost share network operations, particularly in the area of instrument calibrations. Although this proposal has not been formalized yet, SRRAP has agreed to use capital funds to purchase an absolute cavity radiometer, which will be loaned to institutions such as the University of Oregon to perform instrument calibrations traceable to world standards. The absolute cavity radiometer will be available for use in the spring of 1993.

These interactions are leading toward a plan being developed to release, in FY 1993, a request for an announcement to educational institutions and publicly and privately operated solar radiation networks. This announcement would solicit participation in a national monitoring activity through 
a cost-sharing arrangement with NREL. One aspect of this program is to allow networks that are currently facing severe budget and operational cutbacks to remain operational in the context of a national program. This activity will also bring high-quality measurement programs into the national picture so that the density of coverage currently available from the NOAA network can be enhanced greatly at minimal cost to DOE. Further information on this proposed FY 1993 activity is given in Section 4.0.

\subsection{Solar Radiation Research Laboratory Activities}

The Solar Radiation Research Laboratory (SRRL) is located on South Table Mountain in Golden, Colorado, near the NREL offices. SRRL provides the outdnor research measurement capabilities needed by SRRAP and supports other programs at NREL. Since 1979, the development and operation of the laboratory have focused on the following objectives:

- Building a research data base that characterizes solar radiation and meteorological conditions for the various solar technologies.

- Providing a world-class facility for outdoor calibrations of radiometers traceable to international standards.

- Accommodating the varying research needs associated with the development and testing of improved solar radiation instruments, atmospheric models, and solar energy conversion devices.

- Establishing a long-term solar radiation and meteorological and climatological data base for South Table Mountain near Golden, Colorado.

\subsubsection{Research Data Base}

The Baseline Measurement System (BMS) at SRRL collects the 17 data elements listed in Table 3-3. We use a rechargeable battery-powered data acquisition system for sampling the channels every 10 seconds. Five-minute averages are stored in the data logger memory for all but the wind speed and wind direction data, which are instantaneous samples on a 5-minute interval. The data are automatically transferred from the logger memory to ASCII text files on a personal computer each day at midnight. The daily files are transferred to diskettes by a technician during the routine daily maintenance and brought to the Solar Radiation Data Processing Laboratory in the NREL offices. The SRRL data files are processed using the same VAX/FORTRAN software developed for the HBCU solar measurement network. Routine data processing is accomplished with the help of $T$. Ismailidis, a part-time student, who uses a standard procedure. Output products include archived 5-minute data files in NREL Standard Broadband Format with data quality assurance flags, monthly summary reports of hourly and daily values, and off-site storage of the raw and archived data files. A summary of selected measurements processed during FY 1992 are shown in Figure 3-4. With assistance from staff members at the NREL Metrology Laboratory, we performed daily maintenance inspections on the BMS during the weekdays. Maintenance records are written on a standard $\log$ form as part of our quality assurance efforts. More than $95 \%$ of the possible 5-minute data values were recovered during FY 1992. 
Table 3-3. SRRL Baseline Monitoring System Data Channels

\begin{tabular}{|c|l|c|}
\hline No. & \multicolumn{1}{|c|}{ Measurement Parameter } & Instrument* \\
\hline 1 & Global horizontal iradiance & PSP \\
\hline 2 & Diffuse horizontal irradiance & PSP \\
\hline 3 & Direct normal irradiance & NIP \\
\hline 4 & Global irradiance on $40^{\circ}$ south-facing tilt & PSP \\
\hline 5 & Global normal irradiance on two-axis tracking surface & PSP \\
\hline 6 & $\begin{array}{l}\text { Global irradiance on one-axis tracking surface (horizontal, north- } \\
\text { south axis) }\end{array}$ & CM-11 \\
\hline 7 & Global horizontal irradiance $(780$ - 3000 $\mathrm{nm})$ & PSP \\
\hline 8 & Direct normal irradiance (780 - 3000 $\mathrm{nm})$ & NIP \\
\hline 9 & Total-horizontal ultraviolet irradiance $(295-385 \mathrm{~nm})$ & TUVR \\
\hline 10 & Ground-reflected irradiance & PSP \\
\hline 11 & Direct normal irradiance $(500 \mathrm{~nm})$ & LCSP \\
\hline 12 & Wind speed, $10 \mathrm{~m}$ above ground level & TGT \\
\hline 13 & Wind direction, $10 \mathrm{~m}$ above ground level & TGT \\
\hline 14 & Dry-bulb temperature & CSI \\
\hline 15 & Relative humidity & CSI \\
\hline 16 & Barometric pressure & YSI \\
\hline 17 & Direct normal ultraviolet irradiance $(295-385 \mathrm{~nm})$ & TUVR \\
\hline
\end{tabular}

*Instrument abbreviations:

CM-11 = Kipp \& Zonen Pyranometer, model CM-11

CSI = Campbell Scientific, Inc., model 207 Probe

LCSP $=$ NREL-designed low-cost sun photometer (T. Cannon)

NIP = Eppley Laboratory Pyrheliometer, model NIP

PSP = Eppley Laboratory Pyranometer, model PSP

TGT $=$ Teledyne-Geotech Wind System

TUVR $=$ Eppley Laboratory Photometer, model TUVR

YSI $=$ Yellow Springs Instrument Company 


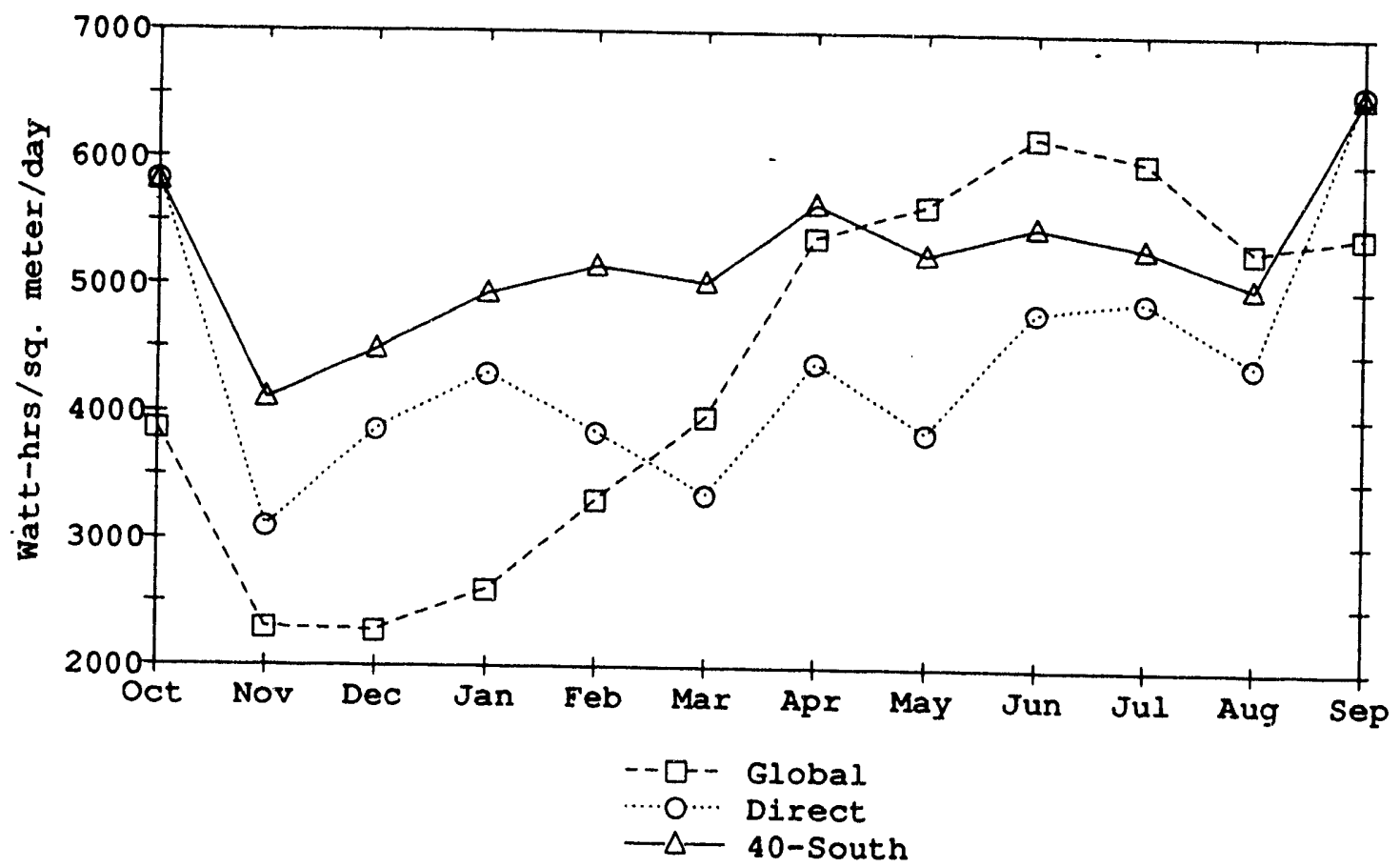

Figure 3-4. Monthly mean daily total radiation measured by the SRRL/BMS during FY 1992

\subsubsection{Radiometer Calibrations}

More than 100 radiometers were calibrated outdoors at SRRL during FY 1992. We continue to refine our Broadband Outdoor Radiometer CALibration (BORCAL) procedures. We maintain a reference group of three electrically self-calibrating absolute cavity radiometers directly traceable to the World Radiometric Reference established by the World Meteorological Organization's World Radiation Center in Davos, Switzerland. Pyrheliometers are calibrated by comparing the voltage signals from the radiometer being tested with the reference direct normal solar radiation as measured with our working standard absolute cavity radiometer. Typically, we use the average of more than 500 such 1-minute comparisons over at least three cloud-free days to determine the mean calibration factor (in $\mu \mathrm{V}$ per $\mathrm{W} / \mathrm{m}^{2}$ ). Pyranometers are calibrated by summing measurements of the reference direct normal solar component, as measured with an absolute cavity, and the diffuse horizontal component, as measured with a thermopile-based pyranometer under a tracking disk. The reference global solar radiation is calculated from these two measurements and the corresponding computed solar zenith angle. We compare the reference radiation with the voltage signal from each pyranometer tested to determine the calibration factor (in $\mu \mathrm{V}$ per $\mathrm{W} / \mathrm{m}^{2}$ ).

During FY 1992, we maintained the calibration traceability of our absolute cavity radiometers by intercomparisons with NOAA's Solar Radiation Facility (SRF) in Boulder, Colo. We also had the opportunity to calibrate 12 pyranometers used by the SRF as references and SOLRAD network instruments. Our calibration results compare favorably with the independent SRF calibrations of the same instruments $( \pm 0.5 \%$ to $\pm 2.5 \%$, depending on the serial number of the instrument). 


\subsubsection{Research Support}

\subsubsection{Testing Rotating Shadowband Radiometers}

Beginning in 1990, the SRRAP cooperated with the NREL Photovoltaics Program and the Electric Power Research Institute (EPRI) to compare several solar radiation measurement systems as options for performing solar radiation assessments in a utility's service territory (Stoffel, Riordan, and Bigger 1991). EPRI acquired instruments called rotating shadowband radiometers (RSR) from two manufacturers who installed them at SRRL for a 6-month comparison with SRRL radiometers. The RSRs (Kern and Russel 1991; Michalsky, Berndt, and Schuster 1986; Michalsky et al. 1988) use a commercially available silicon-detector pyranometer to measure global horizontal radiation, as well as diffuse radiation, when the rotating band blocks the direct radiation during the band's rotation. Direct normal radiation is calculated by subtracting diffuse from global, and by calculating the sun's position from the location, time, and day of the year. Thus, onc instrument is used to obtain values for global, direct, and diffuse radiation. Data from the RSRs were compared with data from the BMS and Reference Irradiance System (RIS) at SRRL. The BMS includes a thermopile-type pyranometer for measuring global horizontal radiation, another pyranometer with a manually adjusted (daily) shadowband measuring diffuse horizontal, and a pyrheliometer mounted in a solar tracker measuring direct normal radiation. Comparisons also were made on selected clear-sky days using data from the RIS. The RIS includes an electrically self-calibrating absolute cavity radiometer for measurements of direct normal radiation and a pyranometer with a tracking shading disk for measurements of the diffuse radiation.

Details of the comparison are available from the final test report prepared at NREL (Stoffel, Riordan, and Bigger 1992). RSR data collection continued during FY 1992.

\subsubsection{Photovoltaic Solar Radiation Research}

SRRAP continued to work closely with the NREL Photovoltaics Program by providing SRRI. facilities and measurement systems (Hulstrom et al. 1993). In particular, SRRL was used for the following:

- To collect and process data from the solar measurement system at the Public Service Company's Ft. St. Vrain power station in Platteville, Colorado, using SRRL/BMS hardware and software.

- To provide photovoltaic (PV) module and cell performance projects with access to selected analog signals f make outdoor measurements and dedicated data acquisition systems.

- To collaborate on the development and characterization of the Atmospheric Optical Calibration System (AOCS) at SRRL. 
- To provide the NREL Thermal Systems Branch with access to the SRRL/BMS data needed for development and operation of its high-flux solar furnace and concentrated ultraviolet detoxification projects located on South Table Mountain.

\subsubsection{FY 1993 Plans for SRRL}

In addition to continuing the maintenance and operation of the ongoing BMS, BORCAL, HBCU, and PV-related solar radiation and meteorological measurement programs at SRRL, by the end of FY 1993, we plan to complete the installation of a basic NREL Local Area Network (LAN) in order to provide researchers with better access to the SRRL data. Future improvements to this system will be the nearly real-time application of existing data quality assurance tests, enabling us to provide better quality information to the users.

B. Marion has also been compiling all the data collected at SRRL to develop a climatology for the site for 1981 to 1991. His report on this effort will be published in early FY 1993.

\subsection{American Society of Heating, Refrigerating, and Air-Conditioning Engineers}

SRRAP personnel actively participate in ASHRAE. More than 50,000 members are in ASHRAE, representing engineers and architects who could benefit from renewable energy technologies. The society in turn offers SRRAP the opportunity to stay informed about user needs. In FY 1992, $T$. Stoffel attended the annual and winter society meetings; participated as a member (vice chair) of the Technical Committee (TC) 4.2, Weather Information; provided technical reviews for society publications and presentations; and served on the Rocky Mountain Regional Chapter of ASHRAE.

As part of our participation in ASHRAE, SRRAP staff members produced a revised meteorological data set called WYEC2. This second version of ASHRAE's Weather Year for Energy Calculations (WYEC) is an expansion of the original data set and ircludes data from the typical meteorological year (TMY) data set prepared for NOAA. Hourly WYEC2 data will be available for 59 cities in the United States and Canada. The surface meteorological data from 1952 to 1975 were retained and combined with solar radiation estimates using the latest modeling techniques. In addition to revised estimates of the direct normal and diffuse solar radiation, the WYEC2 data format includes fields of illuminance and luminance estimates. The WYEC2 data will be distributed with a software "Toolkit" that provides easy access to the data on a personal computer. T. Stoffel will continue to serve as the chair of the ASHRAE/TC4.2 Project Monitoring Subcommittee responsible for the WYEC2 data and software user-interface development. The WYEC2 data, user's manual, and software will be available from ASHRAE.

\subsection{Meeting of the American Solar Energy Society}

Three members of SRRAP participated in the Solar '92 National Solar Energy Conference held from June 13-18, 1992, in Cocoa Beach, Florida. D. Myers presented two papers co-authored with E. Maxwell: "Daily Estimates of Aerosol Optical Depth for Solar Radiation Models" and "Hourly Estimates of Precipitable Water for Solar Radiation Models." B. Marion presented a paper co-authored with C. Riordan and D. Renné: "Solar Radiation Data and Its Applications." 
D. Renne chaired the rescurce assessment division meeting of the American Solar Energy Society (ASES). The group was informed of the schedule for the release of the new National Solar Radiation Data Base (NSRDB).

The recently published document, Shining On: A Primer on Solar Radiation Data, was distributed to 200 conference attendees. We also distributed to 150 conference attendees a brochure announcing NREL's November 1992 workshop, "Recent Advancements in Solar Radiation Resource Assessment Seminar."

\subsection{Other Symposia and Reporting Activities}

SRRAP stoff members remain active in other symposia related to solar energy research and other professio al societies. Several members attended the SOLTECH 1992 conference in Albuquerque, New Mexico, in February 1992. D. Renné and E. Maxwell participated in NREL's Photovoltaic Annual Research and Development Review (PV AR\&D) in Denver, Colorado, on May 13-15. They presented a paper titled "New Capabilities in Solar Resource Assessments" (Renne and Maxwell 1992). The paper and the presentation provided an overview of SRRAP activities and placed yarticular emphasis on the NSRDB. Besides participation in these meetings, C. Riordan prepared a chapter titled, "Solar Radiation Resource Assessment," to be included in the book Advances in Solar Energy.

\subsection{International Activities}

We maintain contacts with a limited number of research organizations working with global meteorological and solar radiation measurements in support of the SRRAP outreach efforts. In particular, we, correspond with Atsumu Ohmura at tne Swiss Geographisches Institut, Claus Fröhlich at the World Radiation Center, Michael Brown and Charles Procell with ASHRAF's International Programs, William Berg at the University of Massachusetts Lowell, and Harlen Chapman at Siemens Solar Industries. Each of these contacts are actively involved in identifying and cataloging sources of international solar radiation and meteorological data.

During FY 1992, we prepared limited assessments of solar radiation availability in northeast Brazil, Pakitan, and India in response to requests from the NREL Photovoltaic Program Office and private industry.

At the beginning of FY 1992, C. Riordan issued her foreign trip report describing her participation in the International Energy Agency's (IEA's) Solar Heating and Cooling Programme Ta.k 17, held at the Fraunhofer Institute in Freiburg, Germany, in September 1991. She was asked to be the leader of Subtask D: Narrowband Spectral Radiation Modeling. However, she was unable to obtain formal approval for this function from DOE, so in the spring of 1992 she resigned her position. Nevertheless, Richard Perez of the State University of New York at Albany is under contract to NREL to provide liaison support to the SRRAP at the International Daylight Monitoring Program (IDMP). Through this liaison activity, he is able to report on the activities of Subtask $D$ because his attendance at thes: meetings is funded through other sources. See Subsection 6.4 for more discussion on Perez's IDMP activities. 


\subsection{Program Outlook}

The FY 1993 annual operating plan (AOP) is somewhat of a departure from previous AOPs of SRRAP in that the plan provides an explicit work breakdown structure (WBS) that addresses the products, data integration, and fundamental research activities in which our program is involved. The FY 1993 WBS, including key SRRAP staff involved in each task area, is shown in Figure 4-1.

The NSRDB will be an important tool for SRRAP activities planned for FY 1993 and beyond. In FY 1993, we will incorporate the NSRDB data into a geographic information system (GIS), which will allow us to display color maps of solar radiation resources for any particular period of time. This work is being led by M. Rymes, with assistance from S. Wilcox and E. Hammond. A black-and-white example of this display, showing annual average daily global horizontal radiation across the United States, is shown in Figure 4-2.

Because the quality of the data elements in the NSRDB have been documented, this display helps establish the certainty of the resource at any location. In a manner similar to that adopted by the wind energy team at Pacific Northwest Laboratory, documented by Elliott et al. (1987), established four certainty ratings. As we complete our mapping activities, we will establish resource values for each grid square of a gridded map of the United States. A certainty rating also will be assigned to each grid square. The map in Figure 4-2 is a preliminary version of this approach and indicates only those areas that we determined to have the lowest level of certainty (shaded areas). These shaded areas indicate regions where a combination of the following conditions exist: (1) no high-quality data exist in the vicinity, and terrain conditions are such that regional data would not be representative of the region being rated and (2) various meteorological and topographical indicators suggest that the resource would be highly variable in the rated region as a result of localized cloud formation and dissipation processes and slope and aspect considerations.

A promising method for enhancing the detail and the certainty of a solar resource map, such as Figure 4-2, is to incorporate surface solar radiation estimates derived from satellite data. This has already been attempted in a number of locations throughout the world using geostationary satellites such as GOES and METEOSAT (Tarpley 1979; Diekmann et al. 1988). The availability of information from the International Satellite Cloud Climatology Project (ISCCP) and the Earth Radiation Budget Experiment (ERBE) also provide an opportunity to expand our understanding of the spatial and temporal distribution of solar resources (Pinker and Laszlo 1992). Beginning in late 1993, we plan to implement a program to incorporate available satellite estimates of surface radiation into the geographic displays of the NSRDB.

We also will use the NSRDB to develop a revised TMY. The current TMY data sets are based on the earlier SOLMET/ERSATZ data base. A new TMY would update this information and would also take advantage of the higher quality information incorporated into the NSRDB. We are in the process of examining different methods from which to develop TMY statistics, and we plan to produce a revised TMY by the end of this year. 


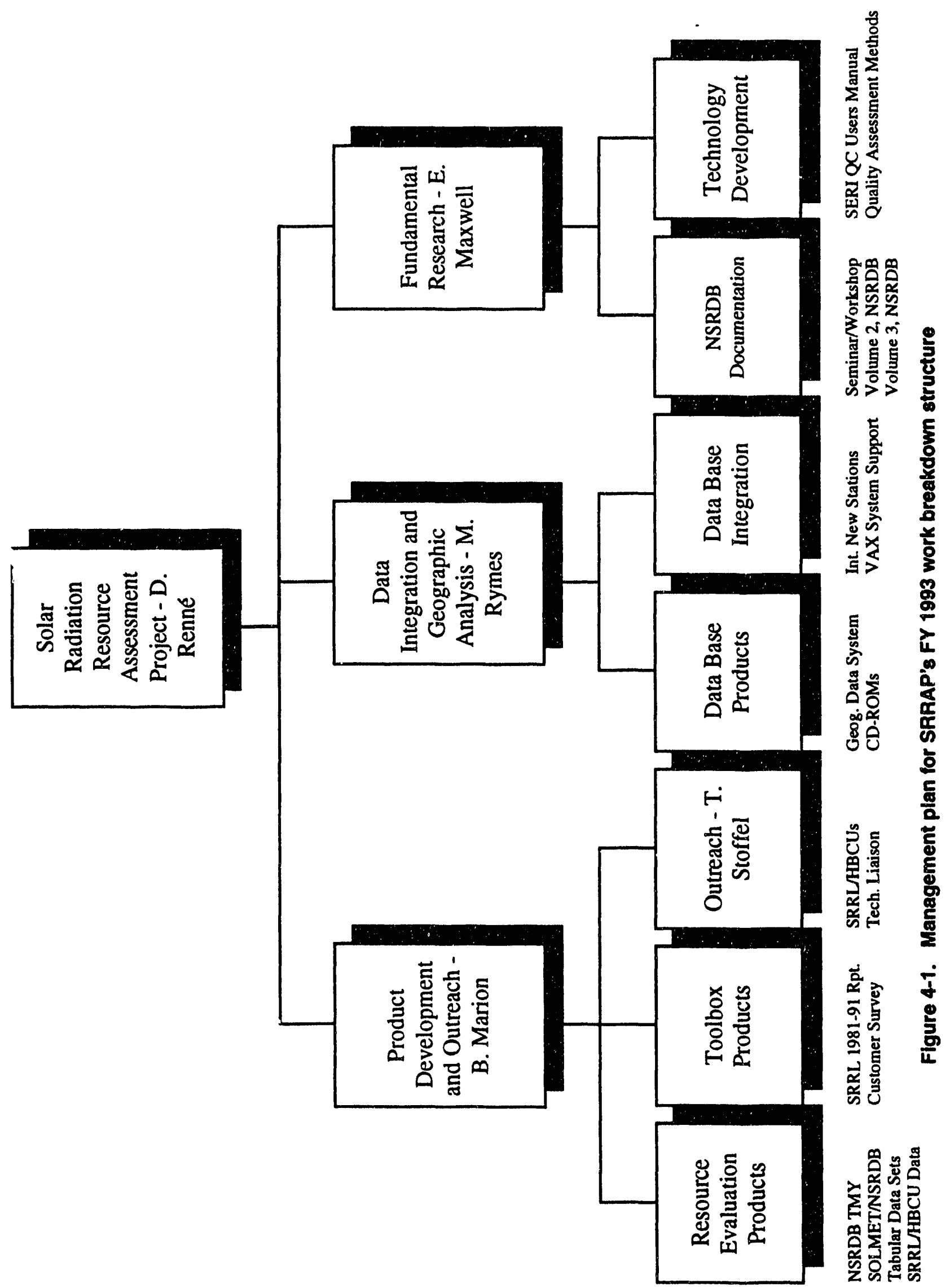




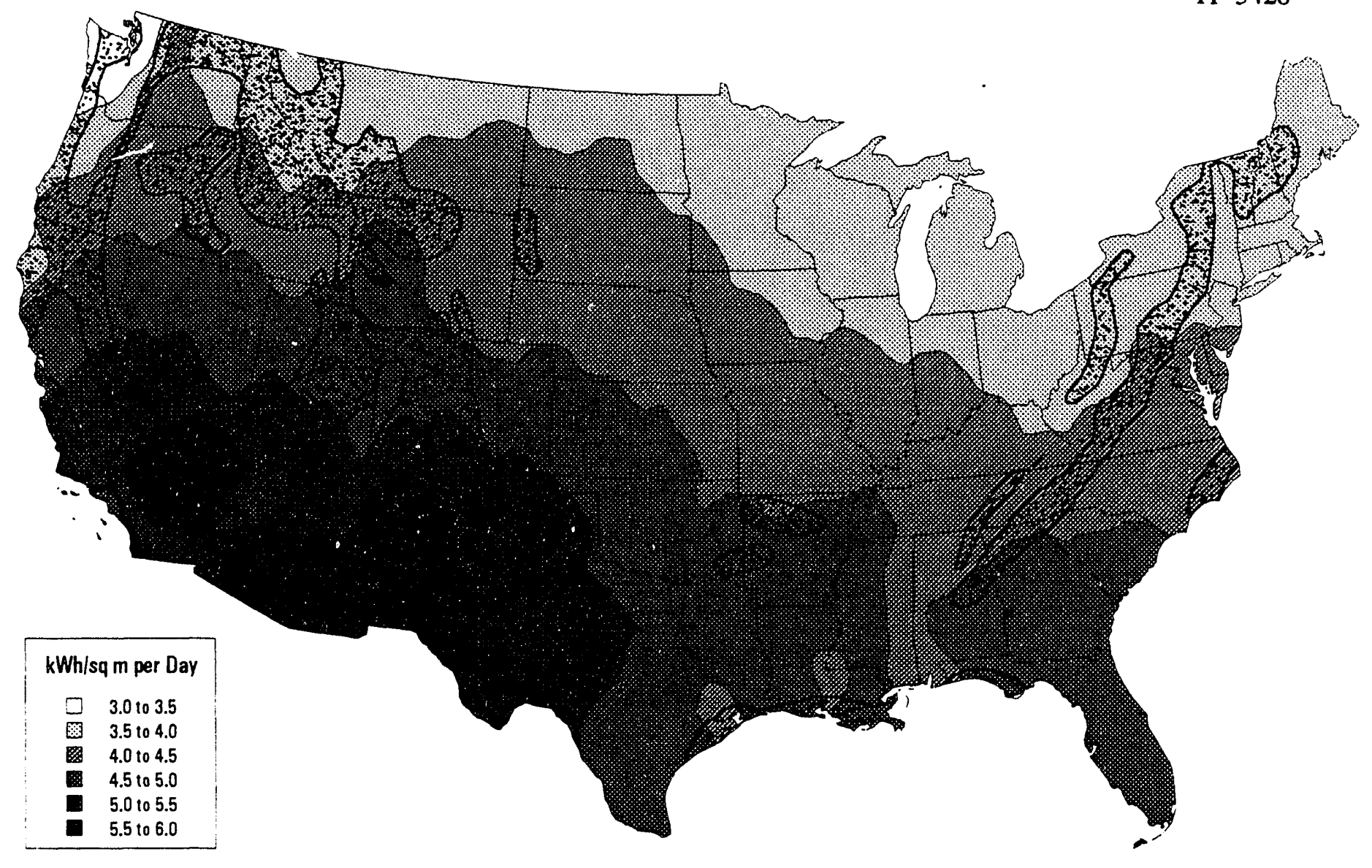

Figure 4-2. Mean annual global horizontal solar radiation, $\mathrm{kWh} / \mathrm{m}^{2} /$ day, based on interpolation of the NSRDB. Cross-hatching represents areas of least certainty in analysis.

Another major activity in SRRAP will be to continue our collaboration with NOAA to ensure that a national network of solar radiation measurements continues in the United States. NREL is expecting to play an active role with NOAA in redefining the U. S. solar radiation network during 1993.

In addition, we will explore other means by which the current network can be expanded. These will involve collaborative arrangements with educational institutions, utilities, and state and private entities operating solar radiation networks and who would like to be involved in a national effort. NREL's role can range from loaning equipment and providing instrument calibrations, to contracting services at locations where measurements are critical but current activities are inadequate. In 1993, we will issue a request for letters of interest (LOIs) to a wide number of potential participants. Responses from interested parties will be evaluated competitively, based on criteria such as the quality of the existing program, its geographic location, and any costs required to upgrade the existing station to make its data quality comparable to other stations in the network.

Besides these activities, we will continue to develop a variety of products that assist industry in making intelligent decisions on deploying renewable technologies. In 1993, we will publish the data quality assessment procedure "SERI QC," which was used extensively in developing the NSRDB. We also will produce a volume of tabular data sets based on the NSRDB. In the fall of 1993, we will publish a data manual similar to the SRRL data manual, covering the entire period 
of record at the HBCUs. We will publish a volume of tabular data sets of use to the PV industry. We will continue our international liaison activities, as well as activities with users of solar energy data outside of the PV industry, such as the IDMP.

Our challenge is to find the most expedient way to provide the highest quality data in a timely fashion and in a useable format to industry. Over the next several years, the federal role in renewable energy resource assessments may expand considerably through a resource assessment budget enhancement. Should this growth occur, we will focus our attention on developing a comprehensive renewable energy data base at NREL, encompassing the five major renewable technology areas (solar, wind, biomass, geothermal, and hydro). This data base will incorporate current or refined resource assessment information developed through a variety of sources. This will be accomplished through a multilaboratory activity so that the experts in each technical field will have an active role in the data base development.

We will make this data base available to the public through the Renewable Energy Resource Assessment Assistance Center at NREL. This center is envisaged to be a highly interactive facility, where users can electronically access renewable energy resource information from anywhere in the country. In addition, the center will produce a number of products and provide a wide range of training services to assist the user community in accessing the information it needs. Included in the GIS will be key market information so that wide-ranging studies involving renewable energy strategies for deployment, as well as for national planning, can be accomplished. The overriding objective of the center will be to assist the renewable energy industry to deploy its technology by making available high-quality planning information aimed at lowering the risk and reducing the uncertainty in planning and shortening project evaluation time. 


\subsection{The New 1961-1990 National Solar Radiation Data Base: Version 1.0}

A major FY 1992 deliverable from SRRAP is the National Solar Radiation Data Base: Version 1.0. Aspects of the NSRDB were discussed in previous annual reports (Riordan et al. 1991; Renné et al. 1992) and other project reports. With the data base now completed, we provide a holistic overview of the process that led to its completion and of the final contents of the data base. In this regard, some of the information in the earlier reports is repeated to present a complete picture of the data base. We begin our discussion with background information regarding the rationale for embarking on the new data base development.

\subsection{Background}

Development of the NSRDB began in FY 1989 after serious consideration was given to the accuracy, completeness, and validity of the data base that was available to the solar radiation community at that time: the SOLMET/ERSATZ data base (SOLMET 1979). This data base, which spanned the period from 1952 to 1975, became available to the solar community in the late 1970 s after an extensive effort to consolidate and assimilate the solar radiation and related information available from the NWS at that time. Many products using the SOLMET/ERSATZ, such as TMY data sets, were subsequently made available to the solar community and became well-established tools for the industry. Thus, along with the decision to embark on updating and refining the existing data base, came the understanding that a large volume of related information also would require updating. Along with this would be the challenge to inform the industry of the availability of these new products and to encourage their use so that a consistent set of new and improved tools were applied to assess renewable energy technologies. In the next sections, we discuss the rationale that led to the decision to embark on this venture. We also discuss the approach that assures the final product meets all our objectives of producing a much-improved data set for the solar industry that met our criteria for accuracy, reliability, and completeness.

\subsubsection{Rationale for Replacing the SOLMET/ERSATZ Data Base}

The SOLMET/ERSATZ data base for the United States was produced during the latter half of the 1970s. SOLMET refers to the combination of solar radiation and meteorological data. This term also is used to identify the 26 stations that collected global horizontal data from 1951 to 1975 . The term ERSATZ refers to the synthetic or modeled solar radiation data that were generated for 222 NWS stations that were not part of the SOLRAD network. This was necessary in order to attain more spatial completeness of the data base.

The global horizontal data collected for the 26 SOLMET stations are the only measured data in that data base. Furthermore, the response of these pyranometers was known to change, as a function of exposure to solar radiation, by as much as $10 \%$ to $15 \%$ over four to six years (Flowers and Starke 1966). In addition, the responses of these instruments were sensitive to changes in the ambient temperature and the angle of incidence of the solar radiation. As a result of these shortcomings, plus uncertainties surrounding the calibrations of these instruments, the measured global horizontal data underwent major modifications. 
These modified global horizontal data were then used to develop clear-sky and cloud regression equations for estimating global horizontal data from sunshine, opaque cloud, sky condition, and precipitation data. The coefficients for the regression equations were unique to each of the 26 SOLMET sites. These regression equations were used to fill in missing data for the 26 SOLMET sites, and they also were used to create global horizontal data for 222 ERSATZ sites.

Unfortunately, the climates of some of the ERSATZ stations could not be well matched with any of the SOLMET sites. For example, the regression equations for Dodge City, Kansas, were used to estimate solar radiation for Denver and Colorado Springs, Colorado. Dodge City is in the middle of the Great Plains, whereas Denver and Colorado Springs are at the foot of the Rocky Mountains. Oth:r questionable matches include Great Falls, Montana, at a latitude of $47.5^{\circ}$, as the reference station for Bettles, Alaska, at $67^{\circ}$ north latitude. Also, Seattle was the reference station for both Barrow, Alaska, on the Arctic Ocean and Redmond, Oregon, which is an inland location at an elevation of 3000 feet. Of course, there were many good climate matches between the SOLMET reference stations and the ERSATZ stations.

Direct normal data for all stations were estimated using regression equations. Global horizontal and direct normal data for five stations (Albuquerque, New Mexico; Fort Hood, Texas; Livermore, California; Maynard, Massachusetts; and Raleigh, North Carolina) were used to develop regression equations to calculate direct normal values from global horizontal values (Randall and Whitson 1977). These few direct normal data were collected from 1974 to 1975, with the exception of Albuquerque (1961 to 1964). The regression equations were used to calculate all of the direct normal data for the 26 SOLMET stations for the entire period of record (16-1/2 to 24 years). Similar regression equations were used to calculate direct normal data for TMY data sets for the 222 ERSATZ stations (NCDC 1981). Comparisons between estimated SOLMET/ ERSATZ direct normal data and measured data collected from 1977 to 1980 revealed large differences - as great as 30\% for monthly means (Randall and Bird 1989).

A number of investigators examined data from the SOLMET data base, as well as the models used in its preparation, and found a great deal of variation in the apparent quality of the SOLMET data. For example, they found differences as great as $20 \%$ in the values for mean monthly global horizontal radiation from the SOLMET data base, which covers 1952 to 1975 , and monthly means from measurements taken from 1977 to 1980. Differences between SOLMET and 1977 to 1980 values for mean monthly direct normal radiation were as great as $50 \%$. This was probably, in part, because the SOLMET data base contained only modeled estimates of direct normal radiation. Randall and Bird (1989) present a good summary of the results of these comparative investigations.

The large differences found between monthly mean values in the SOLMET data base and monthly mean values of data collected by NWS stations from 1977 to 1980 indicated a need to upgrade these values in the data base. However, there was also a need to update. The need to update the data base was because the last data in the SOLMET data base were collected in 1975. This fact, along with the other limitations in the SOLMET/ERSATZ data base described previously, led to the decision by DOE and NREL to undertake, in cooperation with NOAA's National Climate Data Center (NCDC), the effort to update solar radiation measurements in the United States and to develop statistics consistent with standard climatic practices. 


\subsubsection{An Overview of the National Solar Radiation Data Base Project}

\subsubsection{Objectives}

Specific objectives for a new data base were established by DOE, NREL, and NCDC; and a data base development protocol and review process was put into place to assure these objectives were met. The objectives were as follows:

- To produce an updated data base for the period from 1961 to 1990

- To upgrade the existing SOLMET/ERSATZ data base by

- incorporating post-1976 measurements

- improving the rehabilitation of pre-1976 measurements

- developing an improved model capable of estimating statistically and stochastically representative solar radiation data for times and places lacking measurements

- providing improved input data to the model

- producing serially complete hourly values of direct, diffuse, and global solar radiation

- improving the accuracy of the data

- To produce user-friendly products meeting the needs of users.

\subsubsection{Approach and Chronology}

Research and development (R\&D) activities for the NSRDB began in 1989 with work on the development of SERI QC (Maxwell et al. 1989), a software package assessing the quality of solar radiation data. A model to estimate solar radiation from meteorological parameters (now known as the METeorological STATistical model, or METSTAT) began in 1990 and was completed in 1992. Other R\&D activities included the development of a method to synthetically calibrate pyranometers (known as the SYNthetical CALibration, or SYNCAL procedure); development of procedures and algorithms to estimate precipitable water, aerosol optical depth, and surface albedo; and the development of procedures to verify and validate the thousands of lines of code used in the production of the data base. These procedures and algorithms are described in greater detail in the following sections.

The processing of measured sola: radiation data, including quality assessment, also began in 1989 and continued throughout the project period. The acquisition and processing of meteorological data were initiated in mid-1990 and completed during the first quarter of 1992. The final data processing steps, leading to the production of 30 years of data for 5 solar radiation elements and 15 meteorological elements at 239 locations, began in April 1991 and were finished in August 1992. During these 16 months, computers were kept running night and day and through the weekends for extended periods of time.

The users manual for the NSRDB (NREL and NCDC 1992) was completed in September 1992. An Interim Solar Radiation Data Manual (NREL 1992b), containing 30-year statistics for all 239 
stations, was completed in November 1992. Preparation of the final technical report and publication of related journal articles will continue through 1993.

\subsubsection{Review Process}

Expert technical reviews of the design and production of the data base were accomplished in three ways. First, the project was reviewed by the SRRAP Science and Technology Peer Review Committee on three separate occasions-July 28-29, 1988 (preliminary planning); August 16-17, 1989; and December 3-4, 1990. The following were members of the committee:

John Bigger, Electric Power Research Institute

Wayne Darnell, NASA-Langley

Roy Jenne, National Center for Atmospheric Research

Christina Jennings, Pacific Gas \& Electric

Ross McCluney, Florida Solar Energy Center

David Menicucci, Sandia National Laboratories

Frank Quinlan, NOAA-National Climatic Data Center (first meeting only)

David Rodenhuis, NOAA-Climate Analysis Center (last two meetings)

Ronald Stewart, State University of New York-Albany (first two meetings)

Reviews were also accomplished by presenting papers on the overall data base project and on key . parts of the effort. Papers were presented at three annual conferences of the American Solar Energy Society and at the August 1991 meeting of the International Solar Energy Society in Denver, Colorado.

Finally, a data base production update report was sent to 22 external reviewers and 7 internal reviewers. The responses included a number of helpful comments and suggestions that were incorporated into the R\&D and production work.

\subsection{Composite Description of the NSRDB}

The NSRDB is a serially complete collection of hourly values of the three most common measurements of solar radiation (global horizontal, direct normal, and diffuse horizontal). These values were collected over a period of time adequate to establish means and extremes, and at a sufficient number of locations to represent regional solar radiation climates. The solar radiation and meteorological elements contained in the data base are listed in Table 5-1. 
Tabli 5-1. Solar Radiation and Meteorological Elements in the NSRDB

\begin{tabular}{|l|l|}
\hline Global horizontal radiation $\left(\mathrm{Wh} / \mathrm{m}^{2}\right)$ & Atmospheric pressure (millibars) \\
\hline Direct normal radiation $\left(\mathrm{Wh} / \mathrm{m}^{2}\right)$ & Wind direction (increments of $\left.10^{\circ}\right)$ \\
\hline Diffuse horizontal radiation $\left(\mathrm{Wh} / \mathrm{m}^{2}\right)$ & Wind speed $(\mathrm{m} / \mathrm{s})$ \\
\hline Extraterrestrial radiation $(\mathrm{ETR})\left(\mathrm{Wh} / \mathrm{m}^{2}\right)$ & Horizontal visibility $(\mathrm{km})$ \\
\hline Direct normal ETR $\left(\mathrm{Wh} / \mathrm{m}^{2}\right)$ & Ceiling height (decameters) \\
\hline Total sky cover (tenths) & Present weather (10-digit code) \\
\hline Opaque sky cover (tenths) & Total precipitable water $(\mathrm{mm})$ \\
\hline Dry-bulb temperature $\left({ }^{\circ} \mathrm{C}\right)$ & Aerosol optical depth \\
\hline Dew-point temperature $\left({ }^{\circ} \mathrm{C}\right)$ & Snow depth (cm) \\
\hline Relative humidity $(\%)$ & Number of days since last snowfall \\
\hline
\end{tabular}

National and intennational meteorological practices (WMO 1967) call for the use of a 30-year period of record to establish normals, means, and extremes for meteorological variables. Because NOAA updates the normals, means, and extremes for the United States each decade, the period from January 1961 through December 1990 was used for the NSRDB.

Standard International (SI) units are used for all elements in the data base except atmospheric pressure. Atmospheric pressure is reported in millibars (mb) because these units are commonly used in computer models to estimate solar radiation and are consistent with standard NWS reporting practices.

All data are referenced to local standard time. The solar radiation elements are the radiant energy integrated over the hour preceding the designated time. Meteorological elements are the values observed at the designated time.

Measured solar radiation data constitute less than 7\% of the NSRDB, but they provide the benchmark against which model estimates of solar radiation were evaluated. The METSTAT model used for producing approximately $93 \%$ of the solar radiation data in the NSRDB was developed by NREL using the relatively good quality solar radiation data collected by the NWS from 1977 through 1980. These measured and modeled solar radiation data were combined with other meteorological data used by the solar energy industry as part of its system evaluation procedures to form the NSRDB.

When a station contains only modeled solar radiation data, it is referred to as a Secondary station. Primary stations contain measured solar radiation data for at least one year of the 30-year record. 
The NSRDB contains 56 Primary and 183 Secondary stations. Their locations are shown in Figure 5-1.

Two quality flags are attached to each hourly solar radiation element and to many of the meteorological elements. These flags provide information on the source and uncertainty of a data element, allowing each user to evaluate its usefulness. The first flag gives the user information about the source of each hourly value for each solar radiation element, including the methods and input data used to derive model estimates. Solar radiation source flags are defined in Table 5-2. The flags are ranked roughly from highest quality to lowest quality data. However, this ranking may not hold for an individual datum. For example, if the quality assessment of data from a station measuring all three elements of solar radiation (Source Flag A) shows a large probable error in the data, then a large uncertainty will be assigned to the hourly values for each element. This might be a larger uncertainty than that assigned to a modeled value with good quality input data.

The second flag designates the uncertainty attached to each hourly value. The uncertainty flags are defined in Table 5-3. In Version 1.0 of the NSRDB, no flags as low as 1 or as high as 9 were assigned. The uncertainty flags assigned to NSRDB hourly values and statistics of solar radiation were derived using modifications of a standard method developed over the last 15 years by the standards and professional engineering communities (ASME 1985). For the purposes of the NSRDB, uncertainty can be defined as the interval about the reported solar radiation value that is expected to encompass the true value $95 \%$ of the time. For example, all hours for which direct normal radiation is reported to be $1000 \mathrm{Wh} / \mathrm{m}^{2}$, having an uncertainty of $10 \%$, the user can expect that the true direct normal radiation was between 900 and $1100 \mathrm{Wh} / \mathrm{m}^{2} 95 \%$ of the time.

\subsection{Sources of Solar Radiation and Meteorological Data}

NCDC provided solar radiation data collected by NWS. Solar radiation data were also acquired from WEST Associates (a consortium of Southwest utilities), the University of Oregon, three DOE SEMRTS (Solar Energy \& Meteorological Research \& Training Sites), and the NREL HBCU network in the Southeast.

NCDC also provided all of the meteorological data for the entire period of record. The meteorological infornation required for the data base included those data that influence the transmission of solar radiation through the atmosphere, and thus are required to run METSTAT (such as cloud cover information, surface water vapor, and precipitable water from those stations with rawinsodes), and data useful to the solar community (such as surface temperature, wind speed, and wind direction).

\subsubsection{Meteorological Data}

Most of the meteorological data required for the data base were available from the TD-3280 tape deck files at NCDC. TD-3280 files contain data from hourly surface observations. Copies of NCDC archive tapes were sent to NREL, where the variables of interest were extracted. The units were changed to SI units, and gaps in the data record were filled using methods noted in Section 5.3.5. 


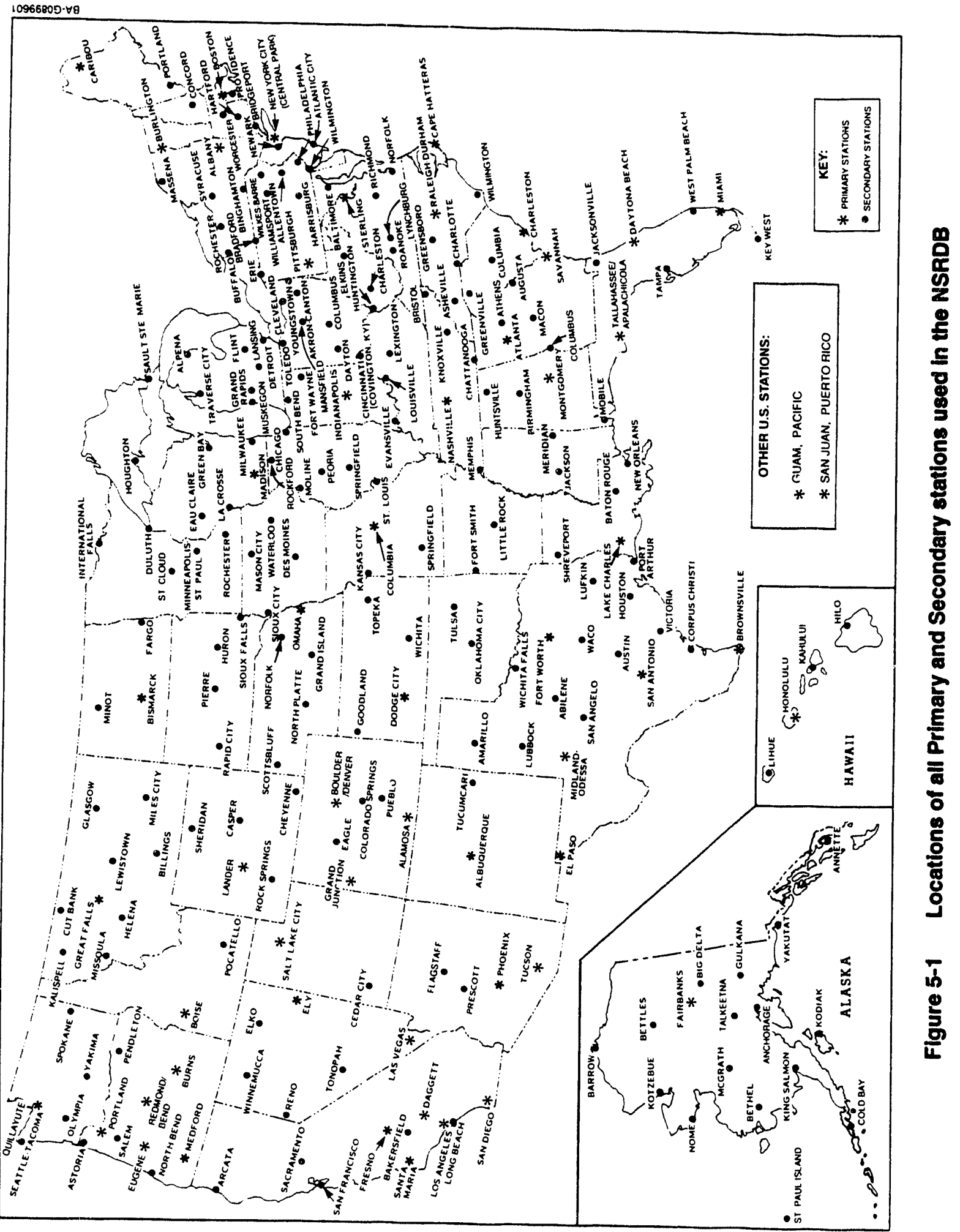


Table 5-2. Solar Radiation Source Flags

\begin{tabular}{|l|l|}
\hline Flag & \multicolumn{1}{|c|}{ Definition } \\
\hline A & $\begin{array}{l}\text { Post-1976 measured solar radiation data as received from NCDC or } \\
\text { other sources }\end{array}$ \\
\hline B & $\begin{array}{l}\text { Same as 'A' except the global horizontal data underwent a calibration } \\
\text { correction }\end{array}$ \\
\hline C & $\begin{array}{l}\text { Pre-1976 measured global horizontal data (direct and diffuse were not } \\
\text { measured before 1976), adjusted from solar to local time, usually with a } \\
\text { calibration correction }\end{array}$ \\
\hline D & $\begin{array}{l}\text { Data derived from the other two elements of solar radiation using the } \\
\text { relation, Kt = Kn + Kd }\end{array}$ \\
\hline E & $\begin{array}{l}\text { Modeled solar radiation data using inputs of observed sky cover (cloud } \\
\text { amount) and aerosol optical depths derived from direct normal data col- } \\
\text { lected at the same location }\end{array}$ \\
\hline F & $\begin{array}{l}\text { Modeled solar radiation using interpolated sky cover and aerosol optical } \\
\text { depths derived from direct normal data collected at the same location }\end{array}$ \\
\hline G & $\begin{array}{l}\text { Modeled solar radiation data using observed sky cover and aerosol opti- } \\
\text { cal depths estimated from geographical relationships }\end{array}$ \\
\hline H & $\begin{array}{l}\text { Modeled solar radiation data using interpolated sky cover and estimated } \\
\text { aerosol optical depths }\end{array}$ \\
\hline$?$ & $\begin{array}{l}\text { Source does not fit any of the above categories. Used for nighttime val- } \\
\text { ues, calculated extraterrestrial values, and missing data. }\end{array}$ \\
\hline
\end{tabular}


Tabie 5-3. Solar Radiation Uncertainty Flags

\begin{tabular}{|c|c|}
\hline Flag & Uncertainty Range (\%) \\
\hline 1 & $0-2$ \\
\hline 2 & $2-4$ \\
\hline 3 & $4-6$ \\
\hline 4 & $6-9$ \\
\hline 5 & $9-13$ \\
\hline 6 & $13-18$ \\
\hline 7 & $18-25$ \\
\hline 8 & $25-35$ \\
\hline 9 & $35-50$ \\
\hline 0 & Not applicable \\
\hline
\end{tabular}

\subsubsection{Precipitable Water}

Development of the NSRDB benefited from a recalculation of precipitable water as part of a DOE-funded climate change project at Columbia University. The calculations were performed at NCDC, under a subcontract from Columbia University, for the period from 1948 to 1988. Data for more thas 70 stations in the United States and Canada were made available to NREL through NCDC. Calculations for 1989 and 1990 and for stations not included in the Columbia University project were done by NCDC under a subcontract from NREL.

The data received from NCDC contained precipitable water values for five atmospheric pressure levels (1013-1000 mb, 1000-850 mb, 850-700 mb, 700-500 mb, and 500-300 mb). Crosscorrelations between the five layers indicated good data integrity. The values in the five layers were summed to obtain total precipitable water from the surface to $300 \mathrm{mb}$. This depth contains the majority (probably $90 \%$ to $98 \%$ ) of precipitable water in the atmospheric column.

Autocorrelation of the total precipitable water data yielded values between 0.9 and 0.6 for lags of 12 and 24 hours, respectively. Based on this, linear interpolation between soundings was used to cbtain hourly values of precipitable water. These hourly values were put into the model used to estimate solar radiation. 


\subsubsection{Snow Depth}

Snow depth data were used for estimating ground albedo. The high surface albedos resulting from snow cover increase diffuse radiation from the clouds and atmosphere. Under partly cloudy skies, this can greatly increase diffuse radiation over the levels that exist when the ground is bare. NREL extracted snow depth data from copies of TD-3210 archive tapes supplied by NCDC.

\subsubsection{Ozone}

Ozone data are not generally available for most locations for the entire period from 1961 to 1990 . However, ozone has a relatively small effect on the transmittance of solar radiation between 0.3 and $3.0 \mu \mathrm{m}$. Thus, monthly mean values of ozone for geographic regions defined by state boundaries and latitude were used as input to the solar radiation model. The monthly mean data were obtained from surface and satellite data. These values were assumed to be the same for each year and were incorporated into the model as a lookup table.

\subsubsection{Filling Gaps in the Meteorological Data}

In order to produce serially complete hourly values of solar radiation data, some meteorological data required as input to the solar radiation model had to be derived or created partly because the data were missing for periods ranging from an hour ' $>$ a y'ar. The causes for missing data are many and include a NOAA cost-saving move in efiect from 1961 to 1981, which called for digitizing only every third hourly observation. The NREL station selection criteria eliminated most stations with TD-3280 data gaps longer than one month, but some sxceptions were found.

In addition to gaps in the data record, there were data elements that were not available at any time for some stations. For one element, aerosol optical depth, the available data were few in number and of uncertcin quality. The manner in which each of these situations were handled is described below.

Short gaps in the data record, for those meteorological elements needed to perform model estimates of solar radiation, were filled by linear interpolation between data points on each side of the gap. The definition of a short gap was a function of the known rate of : hange of the element. Sky cover, for example, was linearly interpolated over gaps as long as $\mathbf{5}$ hours. Total precipitable water was linearly interpolated over gaps as long as 60 hours (five missed soundings). Interpolation between individual sourdiings was used to obtain hourly precipitable water data.

Long gaps in the TD-3280 meteorological data were subdivided inio two categories: (1) 6- to 47-hour gaps and (2) 48-hour to one-year gaps. For gaps 6 to 47 hours in length, data from adjacent time periods of identical length (adjacent to the missing period) were selected to fill the gap. These segments of data were adjusted to match the end pcint values of the gap. For gaps of 48 hours to one year, data frum other years for the same time periods were selected to fill the gap.

No effort was made to fill gaps in the snow depth or present weather data. These discontinuous w/eather events did not lend themselves to any kind of interpolation or substitution methods. 


\subsubsection{Deriving Precipitable Water Data}

There were times and many locations for which no precipitable water data were available from radiosonde soundings. From the work of Garrison and Adler (1990) and others, it was known that long-term monthly means of surface vapor pressure are well correlated with monthly means of total precipitable water.

Research conducted under this project showed similar correlations between hourly surface vapor pressure measurements and precipitable water calculated from individual radiosonde soundings. Therefore, surface temperature, relative humidity, and pressure data were used to derive hourly values of precipitable water for times and locations for which radiosonde data were not available.

\subsubsection{Deriving Broadband Aerosol Optical Depth}

Aerosol optical depth is, and will probably continue to be, the most difficult input parameter to obtain for models that estimate solar radiation at the earth's surface. Although aerosol optical depth measurements have been made at selected wavelengths using sunphotometers, these data are considered to have large uncertainties that become larger when extrapolated to broadband values for the entire solar spectrum (Hallaron 1992; Cachorro, de Frutos, and Casanova 1987; Frohlich 1980). Furthermore, such data are only available for a limited number of locations for limited periods of time.

Given this situation, broadband aerosol optical depth was linked to the METSTAT model used to estimate solar radiation. METSTAT algorithms were used to calculate direct normal transmittances for ozone absorption $\left(T_{O}\right)$, Rayleigh scattering $\left(T_{R}\right)$, absorption of uniformly mi ed gases $\left(T_{U M}\right)$, and watel vapor absorption $\left(T_{W}\right)$. These were combined to obtain a value for molecular transmittance, $T_{M}$

$$
\mathrm{T}_{M}=\mathrm{T}_{\mathrm{O}} \mathrm{T}_{\mathrm{R}} \mathrm{T}_{U M} \mathrm{~T}_{\mathrm{W}}
$$

Aerosol transmittance, $T_{A}$, was then calculated as

$$
T_{A}=\left(I_{N} / I_{O}\right) T_{M}
$$

where $I_{N}$ is the measured direct normal radiation and $I_{O}$ is the extraterrestrial direct normal radiation.

Finally, Beer's law ${ }^{1}$ was used to compute broadband aerosol optical depth, $t_{A}$

where $m$ is relative air mass.

$$
t_{A}=-\ln T_{A} / m
$$

1. Beer's law applies to monochromatic radiation, so its use has represented a modified version. 
This method produced broadband aerosol optical depths for locations and times for which measured direct normal data were already available. The calculated aerosol optical depths were then used to derive seasonal functions for estimating aerosol optical depths for any day of the year. A sine function was found to provide the best fit for the calculated values, as illustrated in Figure 5-2.

Coefficients for the sine functions were then mapped to establish climatic/geographic relationships. These relationships were used to define seasonal functions for all Primary and Secondary stations.

As shown in Figure 5-3, the calculated aerosol optical depths clearly revealed the atmospheric loading that resulted from the volcanic eruption of El Chichon between February 28 and March 4, 1982. Results from lidar measurements of the effects of other volcanic eruptions (Mendonca, Hanson, and DeLuisi 1978) were used to develop lookup tables to represent the effects of other volcanic eruptions from 1961 to 1990 . Although the effects of Mt. St. Helens were undoubtedly very large at locations in the path of its plume, they were short lived. No clear signature of Mt. St. Helens could be derived from the available direct normal data, so the effects of this eruption could not be included.

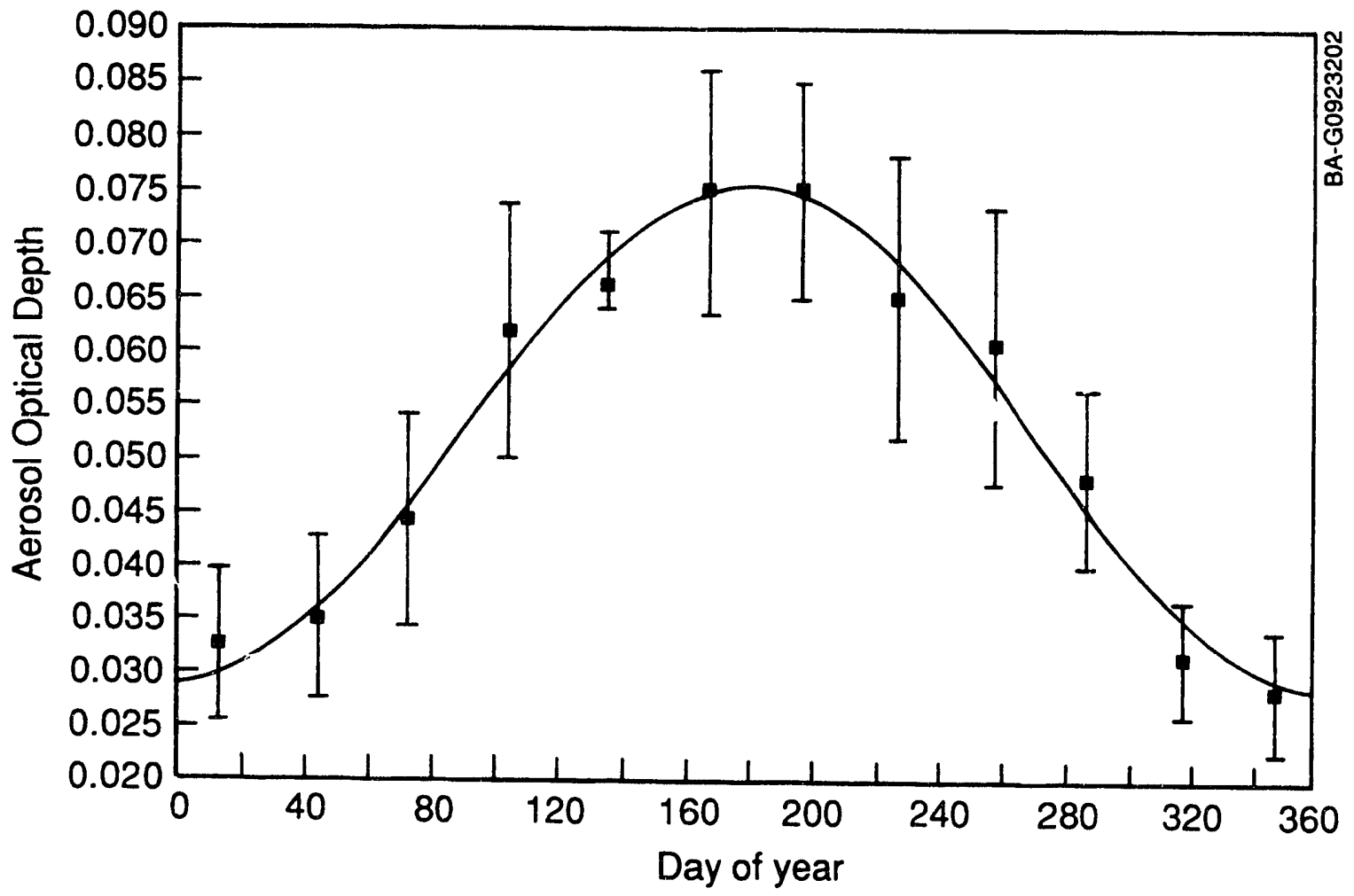

Figure 5-2. Monthly means and standard deviations of broadband aerosol optical depth for all years versus day of the year for Albuquerque. A sine function is fitted to the data. 


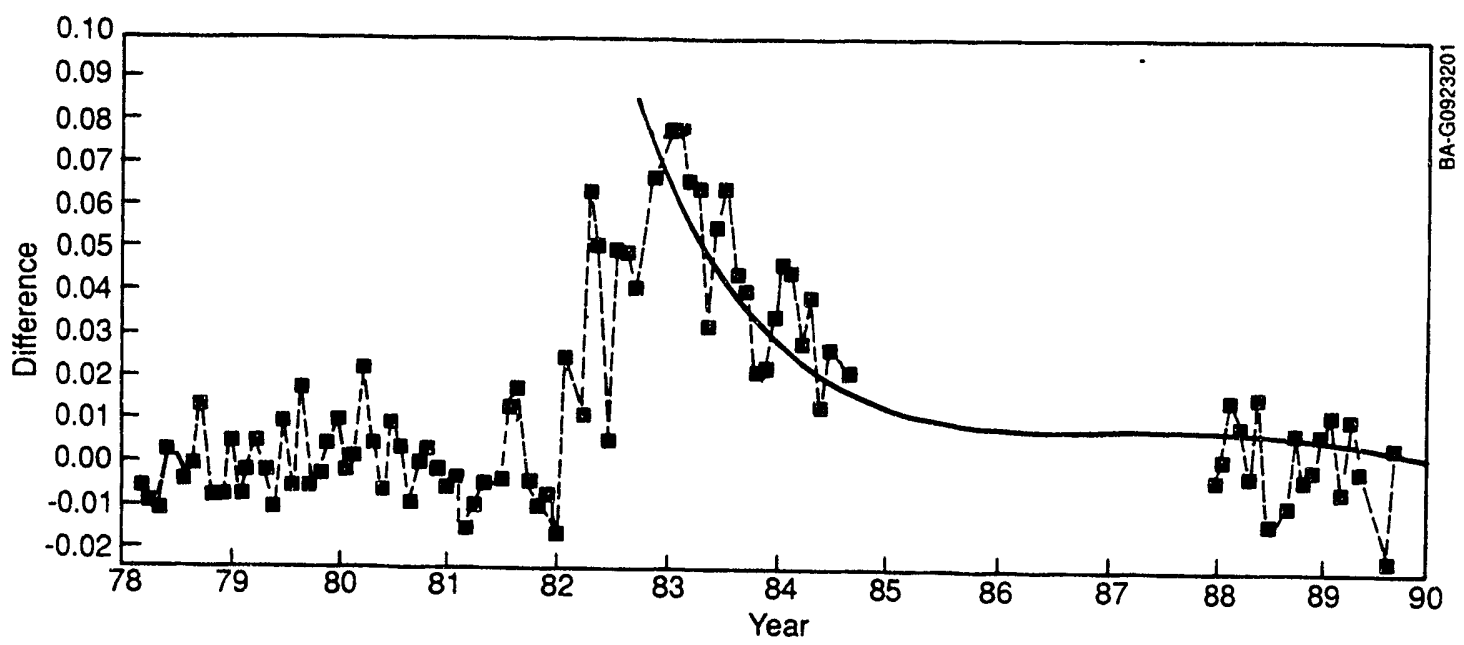

Figure 5-3. Monthly mean differences between calculated aerosol optical depth for individual days and daily values derived from the seasonal sine function for Albuquerque. The solid curve was obtained by smoothing lidar measurements at Mauna Loa, Hawaii, and from SAGE II satellite measurements; it represents stratospheric aerosol optical
depth.

The combination of values derived from seasonal functions and values from the volcanic lookup tables were used to estimate aerosol optical depth for each day from 1961 to 1990 for each of the stations. During the running of the model, these values were randomly varied on a daily basis (using a log normal distribution) to simulate natural variations as reported by Valko (1980) and others. The value actually used by the model for solar radiation calculations was carried into the data base.

\subsection{METSTAT-A Model for Estimating Solar Radiation}

The generation of 30 years of hourly solar radiation data required a computer model capable of accurately simulating the statistical and stochastic characteristics of multiyear solar radiation data sets. It was anticipated that a multiyear data base will most often be used to create design- and typical-year subsets; to establish normals, means, and extremes; and to select or evaluate sites for solar energy systems. Given these uses, it is important that simulated data sets accurately represent the following statistical and stochastic characteristics of measured data:

\section{$\underline{\text { Statistical }}$}

- Monthly moments (mean, variance, skewness, kurtosis)

- Monthly cumulative frequency distributions (cfd's)

\section{Stochastic}

- Diurnal and seasonal patterns

- Hourly and daily autocorrelations

- Cross-correlations between elements (global horizontal, diffuse horizontal, direct normal)

- Persistence 
A block diagram of the meteorological-statistical (METSTAT) solar radiation model developed for the NSRDB (NREL and NCDC 1992) is shown in Figure 5-4. Several features of the model were critical to meeting data base objectives. Hourly calculations using hourly total and opaque cloud cover, hourly precipitable water vapor, daily aerosol optical depth, and daily albedo input data automatically produced representative diurnal and seasonal patterns, daily autocorrelations, and persistence. Placing the statistical algorithms between the input data and the deterministic algorithms led to proper cross-correlations between the direct normal, diffuse horizontal, and global horizontal components. The algorithms are described in greater detail in Appendix B.

\subsection{Synthetic Calibration (SYNCAL) Procedures}

As early as the 1960 s, Flowers and Helfert (1966) recognized the need and the feasibility of compensating for certain solar radiometer response characteristics (temperature and zenith angle) to achieve much improved accuracy in the measurement of solar radiation. Nevertheless, even to this day the procedures they recommended are not usually followed, and single calibration factors are used to process all data.

A general temperature correction of the pre-1976 global horizontal data was effected during the production of the SOLMET/ERSATZ data base (SOLMET 1979). These temperature-corrected data, found in field 109 of the SOLMET data tapes, are the pre-1976 data used for the production of the NSRDB. Furthermore, the pyranometers used for post-1976 measurements were constructed with a temperature correction circuit. Therefore, the SYNCAL procedures described in this section were designed only to correct for the angular response characteristics of pyranometers.

If pyranometer sensor surfaces were always perfectly planar and level, and if the globes surrounding the sensors were always perfectly formed, there would be no azimuth angle differences in pyranometer responses. However, because such imperfections are not infrequent, SYNCAL was designed to correct for both azimuth and zenith angle response characteristics.

It was not possible to use field or laboratory procedures to determine the angular response characteristics of the pyranometers used prior to 1976 because most of these instruments had been lost or broken during shipments. Furthermore, the cost of fully characterizing all of the pyranometers used from 1961 to 1990 would have been prohibitive. Therefore, a synthetic calibration and characterization procedure, using comparisons between modeled and measured global horizontal data, was devised.

Initially, it was planned to use the synthetic calibration procedure only for global horizontal data collected before 1976, when instrument calibrations were almost universally suspect. However, the procedure was also used for post-1976 data, as another check on data quality. Although infrequent, a few apparent calibration problems were found after 1976 that required the use of a calibration correction factor. 


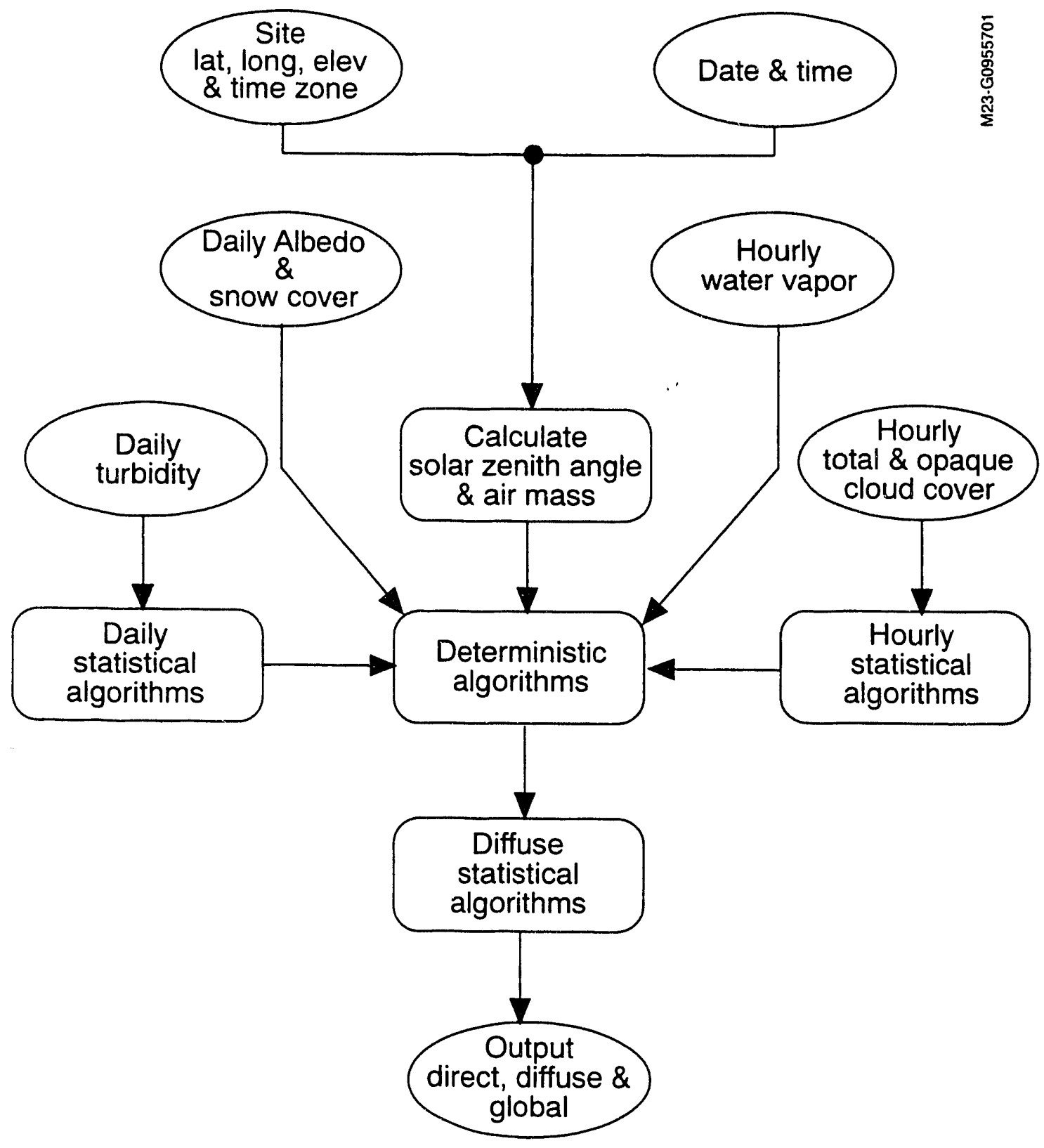

Figure 5-4. Block diagram of the meteorological-statistical (METSTAT) model developed for estimating solar radiation from meteorological parameters 
Because the typical uncertainty for global horizontal data had been determined to be $\pm 5 \%$ (Myers, Emery, and Stoffel, 1989; Wells 1992), a general rule of thumb was adopted whereby apparent calibration errors less than this were ignored. This rule was invoked to avoid uncertain adjustments of measured data to achieve agreement with an imperfect model.

More details of the SYNCAL procedure are given in Appendix B.

\subsection{Comparison of the NSRDB with SOLMET/ERSATZ}

The NSRDB represents a significant improvement over the SOLMET/ERSATZ data base for the following reasons:

- The NSRDB is current, covering the period from 1961 to 1990 and encompassing the effects of any climate changes (natural or man-made) that have occurred since 1975. Projections of system performance into the next century should, therefore, be more accurate.

- $\quad$ NSRDB data are more reliable. Uncertainties for monthly and annual means have been reduced from values as high as $20 \%$ to $30 \%$ to a range of $6 \%$ to $9 \%$. These improvements result from: (1) post-1976 improvements in instrumentation and quality control/ assessment methods, (2) the use of an improved model for estimating solar radiation when measured data are not available, and (3) the use of improved methods for rehabilitating pre-1976 solar radiation data.

- The model developed for the NSRDB was designed to simulate the statistical and stochastic characteristics of measured solar radiation data. Therefore, system performance estimates based on NSRDB data are more likely to be representative of actual performance experience. This is important because more than $90 \%$ of the solar radiation data in both data bases are model estimates.

- All three of the common measures of solar radiation (global horizontal, direct normal, and diffuse horizontal) are available for every hour at every station for the entire 30 years. Therefore, the NSRDB provides data that support all solar applications without regard to the aperture orientation or type of collector used. These solar applications include flatplate PV systems, solar thermal concentrators, and passive daylighting and heating.

- Source and uncertainty flags are attached to every hourly solar radiation value. Therefore, data base users have estimates of the quality of the data they are using, can selectively screen the data for their applications, and can assign uncertainties to their system performance estimates.

- Daily and hourly statistics for each month and each year, as well as the 30-year period of record, have already been produced and are available from NCDC.

Marion and Myers (1992) performed a statistical comparison of the NSRDB with the SOLMET/ ERSATZ data base. They found that, on an annual basis, the NSRDB values for global horizontal 
radiation are within $\pm 5 \%$ of SOLMET/ERSATZ values for $60 \%$ of the stations, more than $5 \%$ greater than the SOLMET/ERRSATZ for $30 \%$ of the stations, and more than $5 \%$ less than the SOLMET/ERSATZ values for $10 \%$ of the stations. They also found that, on an annual basis, the NSRDB values for direct normal radiation are within $\pm 5 \%$ for only $40 \%$ of the stations, more than $5 \%$ greater than the SOLMET/ERSATZ values for $45 \%$ of the stations, and more that $5 \%$ less than the SOLMET/ERSATZ values for $15 \%$ of the stations. Geographically, the NSRDB generally showed higher values of solar radiation for the eastern United States and lower values for some of the western states, although exceptions to this generalization within a given state can also be found.

\subsection{Data Base Products}

Current products available for Version 1.0 of the NSRDB are briefly described here. These products are intended to fit the applications of most data base users. Product options include (1) serial hourly data in two formats, (2) hourly, daily, and quality statistics for solar radiation elements, (3) daily statistics for meteorological elements, and (4) persistence statistics for daily total solar radiation energy.

\subsubsection{Hourly Data}

The serially complete hourly data provided in the data base are available in NSRDB synoptic and TD-3282 formats. Each record in the NSRDB synoptic products contains hourly sequential data for five elements of solar radiation data (three at the surface and two at the top of the earth's atmosphere) and 15 elements of surface meteorological data. The synoptic format also contains quality flags (source and uncertainty) following each solar radiation element and separates each element by one space for greater readability.

TD-3282 is NCDC's archive format featuring daily interleaving of each of the elements specified. Each logical record contains one station's hourly data values for a specific solar radiation or meteorological element for one day. The next record contains hourly data for the same day for the next element; i.e., the elements are interleaved such that all of the elements for one day appear sequentially in a block of 6000 characters. The TD-3282 element file structure is designed to allow maximum flexibility in requesting data.

\subsubsection{Statistical Summaries}

The NSRDB contains statistical summaries computed from the hourly data for the entire period of record for all stations. For the solar radiation data, these statistics include the average and standard deviation of the daily total solar energy (direct normal, diffuse horizontal, and global horizontal) for each station-year-month and each station-year. The 30-year averages and the standard deviations of monthly and annual means from 1961 to 1990 are also provided. For the meteorological elements, only monthly, annual, and 30-year averages were computed. 
The hourly statistical products include monthly, annual, and 30-year averages and standard deviations for each hour of the day for global horizontal, direct normal, and diffuse horizontal solar radiation. The averages can be used to prepare diurnal profiles of hourly solar energy. The hourly values also have been binned in $2450-\mathrm{Wh} / \mathrm{m}^{2}$ bins from 0 to $1200 \mathrm{Wh} / \mathrm{m}^{2}$. The mean number of hourly values falling into each bin have been determined for each station-month for the 30-year period of record from 1961 to 1990 . These statistics can be used to plot histograms and/ or determine cumulative frequency distributions.

A solar radiation persistence product was created for each station-month by calculating the number of times the daily total solar radiation energy persisted above or below set thresholds for periods from 1 to 15 days. These calculations were performed for the entire 30-year period from 1961 to 1990.

Statistics on the quality of the solar radiation data were determined by calculating the percentage of the hourly values to which each source and uncertainty flag was assigned. These percentages were calculated for each station-year and for the 30-year period of record and are available as a separate product.

\subsubsection{Media}

NSRDB synoptic data are available on magnetic media (3.5-in. or 5.25-in. high-density diskettes and high-density magnetic tapes). Data for one year can be placed on one high-density (1.2 megabyte $[\mathrm{MB}]$ ) diskette. All 30 years for two stations can be placed on one high-density magnetic tape. Approximately 120 tapes are required to hold the entire data base. Individual station-years or any combination of stations and years can be ordered from NCDC.

Data in TD-3282 format also are available on magnetic media (3.5-in. or 5.25-in. high-density diskettes or high-density magnetic tapes). Each 1.2-MB diskette can hold ten years of data for a single element or one year of data for all elements. All 30 years of data for two stations can be placed on one high-density magnetic tape.

Daily, hourly, persistence, and quality statistics are available on magnetic media (diskettes and tape), printed hard copy, and microfiche:

- Daily statistics and persistence data for up to 15 stations can be placed on one diskette (3.5-in. or 5.25-in. double-sided, high-density); the daily statistics for all 239 stations can be placed on a high-density magnetic tape. Data can be ordered for selected stations or all stations.

- Hourly statistics for two stations can be placed on each diskette, and hourly statistics for all 239 stations can be placed on two magnetic tapes. Data can be ordered for selected stations or all stations.

- Quality statistics for all 239 stations are available on three diskettes, or they can be ordered in printed form for individual stations. 
- Daily, hourly, and quality statistics for individual stations can be placed on single diskettes.

NCDC also has announced that the data base will be available in CD-ROM format in the spring of 1993. The entire data base will be able to fit on about three CD-ROMs at relatively low cost. By having the NSRDB available in this popular format, the detailed information will soon be accessible to a significantly wider audience than is currently possible. 


\subsection{Program Management}

Routine program management activities in FY 1992 included technical and management interactions with DOE, national laboratories, and other federal agencies; production of monthly status report and six-month self-assessment reviews; preparation of FY 1993 and FY 1994 field work proposals; and preparation of the FY 1993 annual operating plan (AOP). Included in these activities were the continual management of budgets, schedules, and milestones. By the end of FY 1992, SRRAP established a system of providing weekly highlights to DOE/HQ and Sandia. In addition, a number of special activities took place in FY 1992 and are summarized here.

\subsection{Program Reviews}

For the first time, SRRAP participated jointly in semiannual programmatic reviews of NR.EL and Sandia National Laboratory photovoltaics programs. The first review took place in Washington, D.C., in January; the second took place at Sandia, Albuquerque, New Mexico, in July. In each review, SRRAP had the opportunity to present the status and outlook of its activities. For these two reviews, discussions focused on the development and completion of the NSRDB and on areas of interaction between Sandia and NREL. SRRAP participation in these reviews helps to strengthen the connection of the SRRAP products to the photovoltaics industry.

\subsection{Program Planning}

The completion of the NSRDB was a major milestone in SRRAP and provided an opportunity to engage the staff in an extensive planning exercise for FY 1993 and beyond. This planning included an off-site retreat at the Jefferson County Nature Center in August and other frequent interactions among the staff, which ultimately led to the development of the FY 1993 AOP. The structure of this AOP is a considerable departure from previous SRRAP AOPs, and is more in line with the AOPs produced by the NREL and Sandia photovoltaics programs. The SRRAP AOP describes a work breakdown structure (WBS) focusing on three technical areas: Resource Assessment Products and Outreach, led by B. Marion (and includes the management of SRRL and HBCU activities and responses to public inquiries, which are all managed by T. Stoffel); Data Integration, led by M. Rymes; and Fundamental Research, led by E. Maxwell.

The FY 1993 WBS represents a logical follow-on to the activities that led to the completion of the NSRDB in FY 1992 and also positions SRRAP for a potentially large program enhancement that is included in the budget submitted by the Office and Management and Budget for FY 1994. During FY 1992, SRRAP management worked closely with DOE to develop the language that is attached to this enhanced budget proposal. Besides strengthening the core resource assessment program, the enhanced budget calls for the development of a Comprehensive Renewable Energy Resource Assessment Data Base covering all five resource areas (solar, wind, biomass, geothermal, and hydro) and the incorporation of this data base into a geographic information system (GIS). This GIS is structured to allow for external access to resource information by a large segment of our constituency. The technical implications of these proposed budget enhancements were discussed in greater detail in Section 4.0. 
During FY 1992, NREL undertook an effort to develop a 20-year plan for DOE. This plan is designed to address areas of potential laboratory growth and programmatic emphasis. Resource assessment is one of the programmatic areas included in the draft plan, and input was provided by SRRAP management. The input reflects the proposed budget enhancements described in the previous paragraph.

\subsection{Support of DOE's Small Business Innovative Research Program}

The Small Business Innovative Research (SBIR) request for proposals issued in the fall of 1991 (U.S. DOE 1992) included, for the first time, a call for proposals on the development and improvement of broadband and spectral pyranometry. Yankee Environmental Systems of Waltham, Massachusetts, won the competitive bidding with a proposal to develop an improved broadband precision spectral pyranometer by testing several different thermopile configurations based on the "Collander" thermal resistance approach. This was the technique used for measuring irradiance in early pryanometer design. By the end of FY 1992, they eliminated several possible designs and were focusing on one or two promising approaches. Their work is nearing completion, and Yankee is making plans to ship a prototype unit to NREL in early 1993 to be tested at SRRL.

\subsection{Liaison with the International Daylight Monitoring Program}

SRRAP continues to cost-share with DOE's Buildings Program through a contract with R. Perez of the State University of New York at Albany to maintain a general class daylight monitoring station at the Albany campus and to provide general liaison activities between the International Daylight Monitoring Program (IDMP) and SRRAP. With the completion of the NSRDB, the IDMP can use the data as input to daylighting models so that a more complete national view of daylighting characteristics can be developed. The use of daylighting is becoming increasingly important in efficient building design, and this liaison activity is important to help the industry reduce risks in designing buildings for optimizing the use of daylighting.

\subsection{Preparations for Seminar: Recent Advances in Solar Radiation Resource Assessment}

As part of the development of the NSRDB, SRRAP plans included presenting a seminar, available to a wide audience of potential users of the data base, to describe how the data base was developed and how it can be used. E. Maxwell, working with NREL's Conferences group, developed the plans for the seminar, Recent Advances in Solar Radiation Resource Assessment. The planning process became quite intense as the NSRDB neared completion during the summer of 1992.

Announcements about the seminar were mailed to a approximately 3000 possible participants and were distributed at the American Solar Energy Society meeting in Cocoa Beach, Florida. A more detailed agenda was mailed near the end of the summer of 1992. In addition, several outside participants, including government and industry representatives in the United States, as well as international representatives, were invited to give presentations at the seminar. NREL received several preregistrations by the end of FY 1992. Details of the outcome of this seminar, held November 16-19, 1992, in Denver, Colorado, will be reported in the FY 1993 annual report. 


\subsection{Concluding Remarks}

We conclude our FY 1992 annual report by offering some views regarding the federal versus the private role in assessing renewable energy resources. We preface this discussion by asking the question: What is the appropriate federal role for reducing the uncertainties in depicting the extent of our national renewable energy resources? Since the federal government's current focus in the development and deployment of renewable energy technologies includes "market conditioning," i.e., reducing barriers to implementing renewable energy projects, one can argue that a much more aggressive program to improve the spatial and temporal quality of renewable resource data is appropriate. Although NWS data serves an important national need (improved weather forecasting and safe aircraft operations), important uncertainties exist when applying its data to depicting solar energy resources. These shortcomings are offset, in part, through federally sponsored research such as that performed at NREL, which investigates how collateral information can be used to interpolate data to regions where no data exist. Furthermore, a national measurement strategy to accurately depict solar and other renewable resources at all locations would be cost prohibitive.

Since accurate data have value to the renewable energy industry, there is a point at which on-site measurements to reduce the uncertainty in resource characterization within a grid point of a national atlas are more appropriately a private activity. Given the trade-offs between national priorities and the needs of the renewable energy industry, the following scenario for the federal versus the private role in renewable energy resource assessments is suggested.

\subsection{The Federal Role}

The federal government should support the collection of high-quality, calibrated data at a number of representative locations throughout the United States to serve as baseline stations for purposes of assessing renewable energy resources. In Section 3.0, we discussed how a multiagency effort is being proposed to reinstate a high-quality solar radiation monitoring network, improve its performance, and expand its coverage, perhaps at sites other than NWS sites. Other renewable technologies require a similar strategy of high-quality, baseline measurements.

Another federal role is to develop and provide to the renewable energy industry the tools necessary to characterize a specific site through models and interpolation techniques that make use of the data. For example, if appropriate techniques are available to extrapolate nearby longterm data obtained at a "baseline" station to a given site, at an acceptable level of accuracy, then the time to properly evaluate the proposed site can be shortened considerably. Shortening the evaluation time would reduce a major barrier to renewable energy deployment. These tools can include ways to incorporate collateral observations, such as satellite data or data from other agencies and nonfederal data sources, to augment the data base. SRRAP will be focusing its research activities in these areas in future years. 


\subsection{The Private Role}

On-site characterization of renewable energy resources is an appropriate role for the private developer. The developer should have access to the federal data bases and tools with which to make these characterizations and to the state-of-the-art measurement strategies researched by the federal government. Then the developer should implement these tools with his own measurement strategy and use any other modeling or interpolation techniques appropriate to validate the site characteristics that were assessed using the results of federally sponsored research. SRRAP's research objectives are aimed at fulfilling this need for the private sector. 


\subsection{References}

ASME. (1985). American National Standards Institute/American Society of Mechanical Engineers Performance Test Codes PTC 19.1-1985, Supplement on Instruments and Apparatus, Part 1, Measurement Uncertainty.

Cachorro, V.E., de Frutos, A.M., and Casanova, J.L. (1987). Determination of the Angstrom Turbidity Parameters, Applied Optics, Vol. 26, No. 15, pp. 3069-3076.

Diekinann, F.J., et al. (1988). “An Operational Estimate of Global Solar Radiation Irradiance at Ground Level from METEOSAT Data: Results from 1985 to 1987.” Meteor. Rdsch., Vol. 41, pp. 65-79.

Elliott, et al. (1987). Wind Energy Resource Atlas of the United States. DOE/CH 10094-4. Golden, Colorado: Solar Technical Information Program.

Flowers, E.C. and Helfert, N.F. (1966). "Laboratory and Field Investigations of Eppley Radiation Sensors," Monthly Weather Review, Vol. 94, No. 4, pp. 259-264.

Flowers, E.C. and Starke, P.P. (1966). Results of a Field Trip to Compare Pyranometers, unpublished report of the National Oceanic and Atmospheric Administration. Copies available from the Technical Inquiry Service, National Renewable Energy Laboratory, Golden, CO 80401.

Frohlich, C. (1980). Monitoring of Atmospheric Turbidity with Sunphotometers, WMO No. 549, World Meteorological Organization, Geneva, Switzerland.

Garrison, J.D. and Adler, G.P. (1990). "Estimation of Precipitable Water over the United States for Application to the Division of Solar Radiation into its Direct and Diffuse Components," Solar Energy, Vol. 44, No. 4, pp. 225-241.

Hallaron, T.S. (1992). Development of an Automated System to Measure Atmospheric Turbidity, M.S. Thesis, Trinity University, San Antonio, Texas.

Hulstrom, R., Riordan, C., Cannon, T. and Stoffel, T. (1993). Annual Progress Report, Photovoltaic Solar Radiation Research Task, Oct 1991-Sept 1992. NREL/TP411-5013. National Renewable Energy Laboratory, Golden, CO.

Kem, E. and Russel!, M.C. (1991). "Rotating Shadow Band Pyzanometer Irradiance Monitoring for Photovoltaic Generation Estimation," Proc. Twenty Second IEEE Photovoltaic Specialists Conference, October 7-11, Las Vegas, NV. Vol. 1, pp. 541-546.

Marion, W. and Myers, D. (1992). A Comparison of Data from SOLMET/ERSATZ and the National Solar Radiation Data Base. NRELTP-463-5118. National Renewable Energy Laboratory, Golden, CO. 
Maxwell, E.L., Rymes, M.D., Stoffel, T.L. and Myers, D.R. (1989). "Post Measurement Quality Control of Solar Radiation Data," Proc. American Solar Energy Conference, Denver, CO.

Mendonca, B.G., Hanson, K.J., and DeLuisi, J.J. (1978). "Volcanically Related Secular Trends in Atmospheric Transmission at Mauna Loa, Hawaii," Science, 202, pp. 513-515.

Michalsky, J.J., Berndt, J.L., and Schuster, G.J. (1986). "A Microprocessor-based Rotating Shadowband Radiometer," Solar Energy, Vol. 36, No. 3, pp. 465-470.

Michalsky, J.J., Perez, R, Stewart, R. LeBaron, B.A. and Harrison, L. (1988). "Design and Development of a Rotating Shadowband Radiometer Solar Radiation/Daylight Network," Solar Energy, Vol. 41, No. 6, pp. 577-581.

Myers, D.R., Emery, K.A., and Stoffel, T.L. (1989). "Uncertainty Estimates for Global Solar Irradiance Measurements Used to Evaluate PV Device ‘.rformance," Solar Cells, Vol. 27, pp. 455-464.

National Climatic Data Center (NCDC). (1981). Typical Meieorological Year User's Manual TD 9734, Hourly Solar Radiation-Surface Meteorological Observations. NCDC, Asheville, NC.

National Renewable Energy Laboratory. (1992a). Shining On: A Primer on Solar Radiation Data. NREL TP-463 4856. DE92010555. National Renewable Energy Laboratory, Golden, CO.

National Renewable Energy Laboratory. (1992b). Interim Solar Radiation Data Manual, NREL TP-463-5176, National Renewable Energy Laboratory, Golden, CO.

National Renewable Energy Laboratory and National Climatic Data Center. (1992). Users Manual: National Solar Radiation Data Base (1961 - 1990). Prepared by National Renewable Energy Laboratory, Golden, CO. Distributed by National Climatic Data Center, Asheville, NC.

Pinker, R.T., and Laszlo, I. (1992). "Modeling Surface Solar Irradiance for Satellite Applications on a Global Scale," J. Appl. Met., Vol. 31, pp. 194-211.

Randall, C.M. and Bird, R. (1989). "Insolation Models and Algorithms," in Solar Resources, R.L. Hulstrom, ed., The MIT Press, Cambridge, MA. Chap. 3. pp. 61-144.

Randall, C.M., and Whitson, M.E. Jr. (1977). hourly Insolation ana' Meteorological Data Bases Including Improved Direct Insolation Estimates, Aerospace Repūit. No. ATR-78(7592)-1, 1 December 1977, The Aerospace Corporation, El Segundo, CA.

Renné, D. and Maxwell, E. (1992). "New Cápabilities for Solar Resource Assessments," in Photovoltaic Advanced Research and Development Project, Rommel Noufi, ed., AIP Conference Proceedings 268, Denver, Colorado. American Institute of Physics.

Renné, D., Riordan, C., Maxwell, E., Stoffel, T., Marion, B., Rymcs, M., Wilcox, S., Myers, D., Hammond, E. and Ismailidis, T. (1992). NREL Solar Radiation Resource Assessment Project: 
Status and Outlook, FY 1991 Annual Progress Report, NREL/TP-262-4679, National Renewable Erergy Laboratory, Golden, CO.

Riordan, C., Maxwell, E., G., Stoffel, T., Rymes, M. and Wilcox S. (1991). SERI Solar Radiation Resource Assessment Project: Fiscal Year 1990 Annual Progress Report, SERI/TP-262-4118, Solar Energy Research Institute, Golden, CO.

SERI. (1988). Standard Broadband Format, A Solar and Meteorological Data Archival Format. SERI/SP-320-3305, Solar Energy Research Institute, Golden, CO.

SOLMET. (1979). Vol. 2, Final Report-Hourly Solar Radiation: Surface Meteorological Observations. TD-9724, National Climatic Data Center, Asheville, NC.

Stoffel, T., Riordan, C. and Bigger, J. (1991). "Joint EPRI/SERI Project to Evaluate Solar Radiation Measurement Systems for Electric Utility Solar Radiation Resource Assessment," Proc. Twenty Second IEEE PV Specialists Conference, October 7-11, Las Vegas, NV, Vol. 1, pp. 533-540.

Stoffel, T., Riordan, C. and Bigger, J. (1992). Evaluation of Solar Radiation Measurement Systems: EPRL/NREL Final Test Report, Volume 1, NREL/TP-463-4771, National Renewable Energy Laboratory, Golden, CO.

Tarpley, J.D. (1979). "Estimating Incident Solar Radiation at the Surface from Geostationary Satellite Data." J. Appl. Met., Vol. 18, pp. 1172-1181.

U.S. Department of Energy. (1992). Small Business Innovation Research, Program Solicitation, DOE/ER-0504, U.S. Department of Energy, Washington, DC.

Valko, P. (1980). "Some Empirical Properties of Solar Radiation and Related Parameters," DOE/ ER-0084, IEA Task IV, in An Introduction to Meteorological Measurements and Data Handling for Solar Energy Applications, U.S. Department of Energy, Washington, DC.

Wells, C.V. (1992). "Measurement Uncertainty Analysis Techniques Applied to PV Performance Measurements," Proceedings Photovoltaic Performance and Reliability Workshop, National Renewable Energy Laboratory, Golden, $\mathrm{CO}$.

WMO. (1967). A Note on Climatological Normals, WMO No. 208, T.N. No. 84, World Meteorological Organization, Geneva, Switzerland. 


\section{Appendix A \\ FY 1992 Publications by the Solar Radiation Resource Assessment Project}

NSRDB-Volume 1, User's Manual - National Solar Radiation Data Base (1961-1990). Version 1.0., National Climatic Data Center, Asheville, NC.

Marion, W., Riordan, C., Renné, D. Shining On: A Primer on Solar Radiation Data, NREU TP463-4856, National Renewable Energy Laboratory, Golden, CO (May 1992).

Marion, W., Renné, D., Riordan, C. "Solar Radiation Data and Its Applications." Proceedings of the 1992 Annual American Solar Energy Society Conference, June 15-18, 1992, Cocoa Beach, FL, pp. 350-355.

Maxwell, E.L. and Myers, D.R. "Daily Estimates of Aerosol Optical Depth for Solar Radiation Models." Proceedings 21st ASES Annual Conference, March 13-19, 1992, Cocoa Beach, FL.

Maxwell, E.L. and Myers, D.R. "Hourly Estimates of Precipitable Water for Solar Radiation Models." Proceedings 21st ASES Annual Conference, March 13-19, 1992, Cocoa Beach, FL.

Stoffel, T., Riordan, C., Bigger, J. Evaluation of Solar Radiation Measurement Systems: EPRV NREL Final Test Report, Vol. 1, NRELTP-463-4771, National Renewable Energy Laboratory, Golden, CO.

Renné, D. and Maxwell, E. "New Capabilities for Solar Resource Assessments," in Photovoltaic Advanced Research and Development Project, Rommel Noufi, ed., AIP Conference Proceedings 268, Denver, Colorado. American Institute of Physics.

Renné, D., Riordan, C., Maxwell, E., Stoffel, T., Marion, W., Rymes, M., Wilcox, S., and Myers, D. NREL Solar Radiation Resource Assessment Project: Status and Outlook FY 1991 Annual Progress Report, NREL/TP-262-4679, National Renewable Energy Laboratory, Golden, CO (May 1992). 


\section{Appendix B \\ Detailed Descriptions of the METSTAT Model and the SYNCAL Procedures Used in the NSRDB}

The deterministic algorithms were designed to meet the objective of creating data sets with accurate monthly means. The statistical algorithms randomly varied input parameters (cloud cover and aerosol optical depth) such that monthly data sets exhibit representative statistical characteristics. Daily rather than hourly variations of aerosol optical depth are generally representative of nature and served to retain the smooth diurnal patterns that are observed under cloudless skies.

Basically, METSTAT (meteorological-statistical) is a parametric model that relates meteorological parameters to solar radiation at the earth's surface. The cloudless sky algorithms were initially developed by Bird and Hulstrom (1981) using physical radiative transfer models to derive much simpler parametric algorithms. For METSTAT, a heuristic approach was used to verify and modify (as needed) Bird's cloudless sky algorithms and to develop new empirical algorithms relating the effects of clouds on surface radiation. Although the cloud effect algorithms were not derived from the physical processes of absorption and scattering of radiation by the water droplets in the clouds, care was taken to ensure that they represented the results of these processes.

\section{Direct Normal Algorithms}

\section{Cloudless Sky Transmittance}

The cloudless sky direct normal transmittance algorithms are essentially those given by Bird and Hulstrom (1981) and Iqbal (1983) (Parameterization Model C). The only exceptions are the algorithm for water vapor absorption and the algorithm for the combined effect of aerosol absorption and scattering, which were somewhat modified. All of these algorithms are broadband (solar spectrum) parameterizations and include

- Transmittance of ozone absorption $\left(\mathrm{T}_{\mathrm{O}}\right)$

- Transmittance of Rayleigh scattering $\left(T_{R}\right)$

- Transmittance of uniformly mixed gases, $\mathrm{CO}_{2}$, and $\mathrm{O}_{2}\left(\mathrm{~T}_{\mathrm{UM}}\right)$

- Transmittance of water vapor absorption $\left(\mathrm{T}_{\mathrm{W}}\right)$

- Transmittance of aerosol absorption and scattering $\left(T_{A}\right)$

- Transmittance of aerosol absorption $\left(\mathrm{T}_{\mathrm{AA}}\right)$

- Transmittance of aerosol scattering $\left(\mathrm{T}_{\mathrm{AS}}\right)$.

\section{Cloud Transmittance}

The parametric cloud transmittance algorithms were developed using subsets of data assembled from National Weather Service (NWS)-SOLRAD network stations for the years from 197? through 1980. The variables for data in the subsets were fixed within narrow ranges and came from across the United States for all months of the year. This reduced the probability of develop- 
ing algorithms that would exhibit regional or seasonal biases. The cloud effect algorithms included

- Opaque sky cover transmittance ( $\left.\mathrm{T}_{\mathrm{OPQ}}\right)$

- Translucent (total-opaque) sky cover transmittance $\left(\mathrm{T}_{\mathrm{TRN}}\right)$.

The total direct normal transmittance $\left(T_{N}\right)$ is then given by

$$
T_{N}=T_{O} T_{R} T_{U M} T_{W} T_{A} T_{O P Q} T_{T R N}
$$

\section{Diffuse Horizontal Algorithms}

\section{Atmospheric Scattering}

The deterministic algorithms that estimate the diffusion of radiation by the atmosphere are

- $\quad$ Rayleigh diffusion $\left(\mathrm{KS}_{\mathrm{R}}\right)$

- $\quad$ Aerosol diffusion $\left(\mathrm{KS}_{\mathrm{A}}\right)$.

\section{Scattering by Clouds}

The deterministic algorithms that estimate the scattering of solar radiation by clouds are

- Opaque cloud scattering $\left(\mathrm{KS}_{\mathrm{OPO}}\right)$

- Translucent (total-opaque) cloud scattering $\left(\mathrm{KS}_{\mathrm{TRN}}\right)$.

\section{Multiple Surface-to-Atmosphere/Cloud Reflections}

Some of the solar radiation incident on the earth's surface is scattered back toward the atmosphere. Some of this backscattered radiation is in turn scattered back to the surface by the atmosphere and/or clouds. This multiple scattering process serves to increase the total diffuse radiation incident upon the surface. The intensity of these multiple surface-to-atmosphere/cloud reflections is a function of the albedo of the surface and the atmosphere and clouds.

This process is of greatest significance when there is snow on the ground under partly cloudy skies. The model algorithm calculates daily values of surface albedo from snow depth, a terrain factor, and the number of days since the last snow storm. These algorithms are based, in part, on the work of Baker, Skaggs, and Ruschy (1991) and Baker, Ruschy, and Wall (1990), who studied the reduction of albedo with time (days since last snowfall) and the effects of vegetative ground cover and snow depth.

In the absence of snow cover, monthly values of surface albedo were based on a general knowledge of ground cover and the reflectance of cover types and on satellite images. Atmospheric albedo was based on aerosol effects; the albedo of clouds was determined from the product of cloud cover and assigned reflectances for opaque and translucent clouds. 


\section{Precipitation Switch}

The final factor affecting diffuse radiation is precipitation. Rain is usually, although not always, accompanied by a darkening of the sky. Therefore, the precipitation switch reduces diffuse radiation when rain or hail is recorded and when opaque sky cover exceeds 7 tenths.

A study of diffuse data yielded no evidence that precipitation in the form of snow significantly affected the diffuse radiation incident upon a horizontal surface. Hence, the precipitation switch does not respond to snowfall.

\section{Statistical Algorithms}

\section{Cloudless Sky Algorithms}

Under cloudless skies, it was assumed that the hour-to-hour variations of solar radiation would depend primarily on the solar zenith angle. Hourly variations of water vapor and aerosol optical depth do occur, but the hourly changes are usually small. This results in the smooth diurnal variations of solar radiation that are commonly observed under cloudless skies.

The hourly variations of water vapor were obtained from linear interpolations between the twice daily radiosonde soundings or from hourly observations of surface vapor pressure. Therefore, it was not necessary to apply a statistical algorithm to water vapor.

From Valko (1980), it was noted that daily variations of aerosol optical depth exhibit a lognormal distribution around the monthly mean. This was verified from our calculations used to determine monthly means. Therefore, a lognormal distribution function was used to effect random variations of aerosol optical depth on a daily basis.

\section{Random Effects of Cloud Cover}

The random effects of cloud position, type, and size dominate the random variation of the direct normal component of solar radiation. The standard deviation of direct normal radiation for research data subsets with 4,6 , and 8 tenths opaque cloud cover was found to be two to four times greater than the standard deviation under cloudless or overcast skies. It is probable that the position of the clouds with respect to the sun and the observer is the controlling factor; therefore, these combined effects will be referred to as cloud position effects.

The cumulative frequency distributions (cfd's) of direct normal radiation for low aerosol optical depth and low water vapor conditions were used to derive the cfd's representing the random effect of opaque cloud position and are shown in Figure B-1. A random number generator with a uniform distribution from 0 to 1 was used with tables of the cfd's to obtain values of effective opaque sky cover. These values were used to calculate opaque sky cover transmittance by substituting effective opaque sky cover for observed opaque sky cover.

From Figure B-1, it is noted that the cfd's for 0 and 10 tenths observed opaque sky cover allow for actual sky covers between 0 to 0.5 tenths and 9.5 to 10 tenths, respectively. Therefore, as the cfd's 


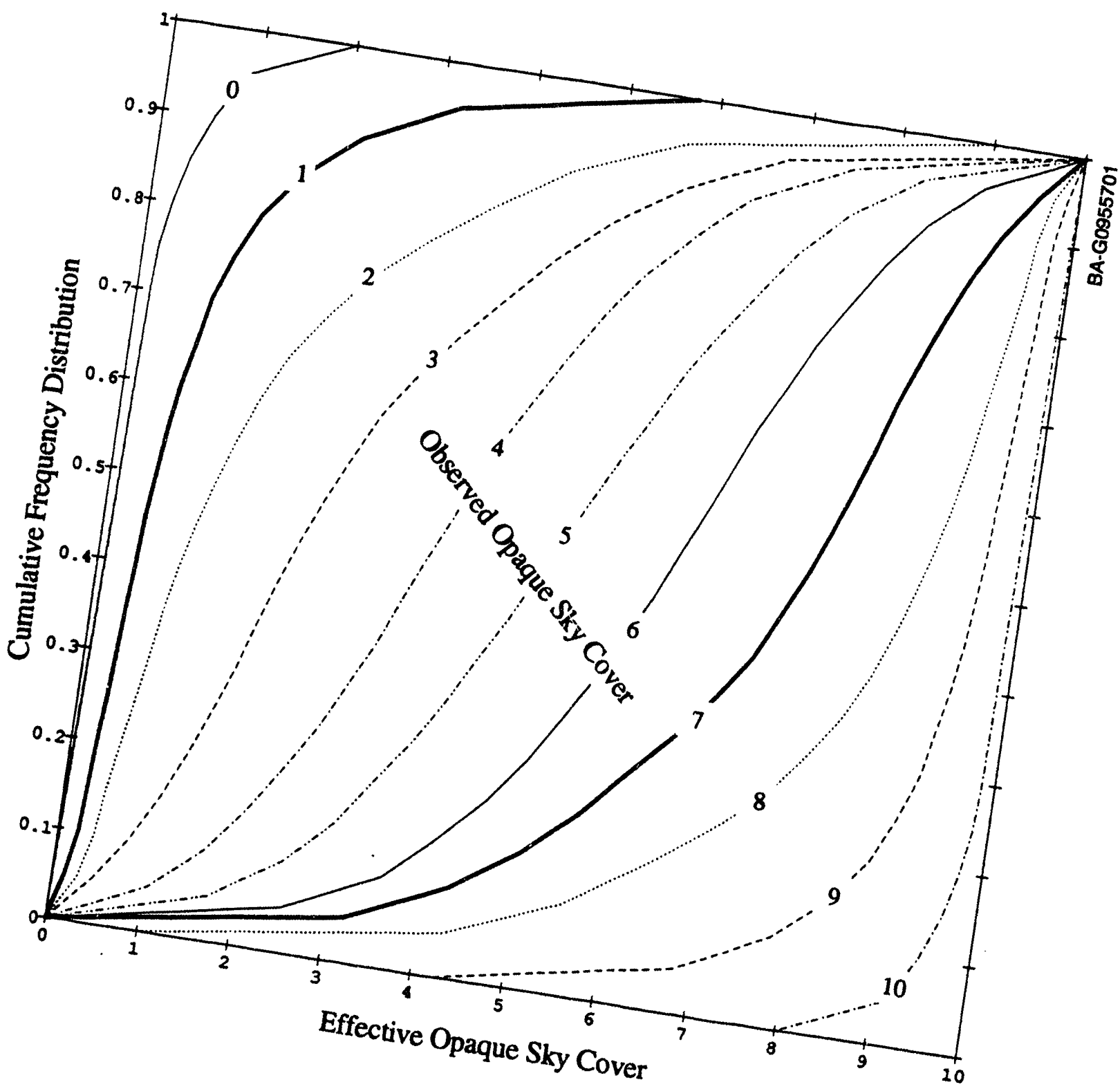

Figure B-1.

Cumulative frequency distributions (cfd's) of effective opaque cloud cover for each
of the 11 values of observed opaque cloud cover. (Derived from cfd's for direct nor.
mal data for clear-dry atmospheres with no translucent clouds.) 
indicate, under reported cloudless skies, there is a small but finite probability that the sun will be occluded by a small cloud for a small part of the hour. Likewise, under reported overcast skies, there is a small probability that the sun will shine through a small break in the clouds for a short time.

However, there are conditions under which the sky will be truly clear or overcast for several hours or days at a time. Under these conditions, the probability of a stray cloud or a break in the clouds becomes very small. Therefore, whenever unbroken sequences of cloudless or overcast hours occurred, the range of values from the random number generator was restricted. For instance, for the second cloudless or overcast hour, the random number generator was restricted to values from 0 to 0.9 or 0.1 to 1.0 , respectively. For 3 sequential hours the values were restricted to 0 to 0.8 and 0.2 to 1.0, etc.; until for sequences of clear or overcast hours of 10 or more, the values were restricted to 0 to 0.1 and 0.9 to 1.0 , respectively. This essentially eliminates the skewed portions of the cfd. This procedure ensured the generation of a smooth diurnal solar radiation pattern for truly cloudless and overcast days.

The random variations of the input variables (turbidity and cloud cover) did not produce sufficient variation of the diffuse element of solar radiation. Therefore, as indicated in Figure B-2, additional statistical algorithms, following the deterministic algorithms, were used to increase the hour-io-hour variation of the diffuse element.

\section{Development of the Calibration Correction Factors}

The SYNCAL procedure that was used to derive calibration correction factors (CCFs) for global horizontal measurements involved several steps briefly described here:

Step 1: The dates during which each pyranometer was in use at each station in the National Oceanic and Atmospheric Administration (NOAA) SOLRAD network were determined from SOLMET Vol. 2.0 (SOLMET 1979) and from handwritten station records obtained from NOAA's Solar Radiation Facility in Boulder, Colorado. For non-NOAA stations, it was initially assumed that the same pyranometer had been used during the entire period of record for the station. The following steps were then performed for each instrument that had been used at each station.

Step 2: Total sky cover data were used to select those hours with no reported clouds. Because solar radiation data represent the integration of energy during the 60 minutes preceding the hour, only cloudless sky hours preceded by a cloudless sky hour were used to calculate calibration correction factors. Calculations also were limited to hours with zenith angles less than $80^{\circ}$ at the midpoint of the hour. Both measurements and model estimates were considered to be too uncertain for larger zenith angles.

Step 3: Using the hours selected from Step 2, the ratio of modeled estimates to measured global horizontal radiation were used to obtain a calibration correction factor $\left(\mathrm{CCF}=\mathrm{Ig}_{\text {mod }} / \mathrm{Ig}_{\text {meas }}\right)$. The hourly CCFs were then used to calculate daily average CCFs that were used to generate time series plots of the correction factors for each instrument. 


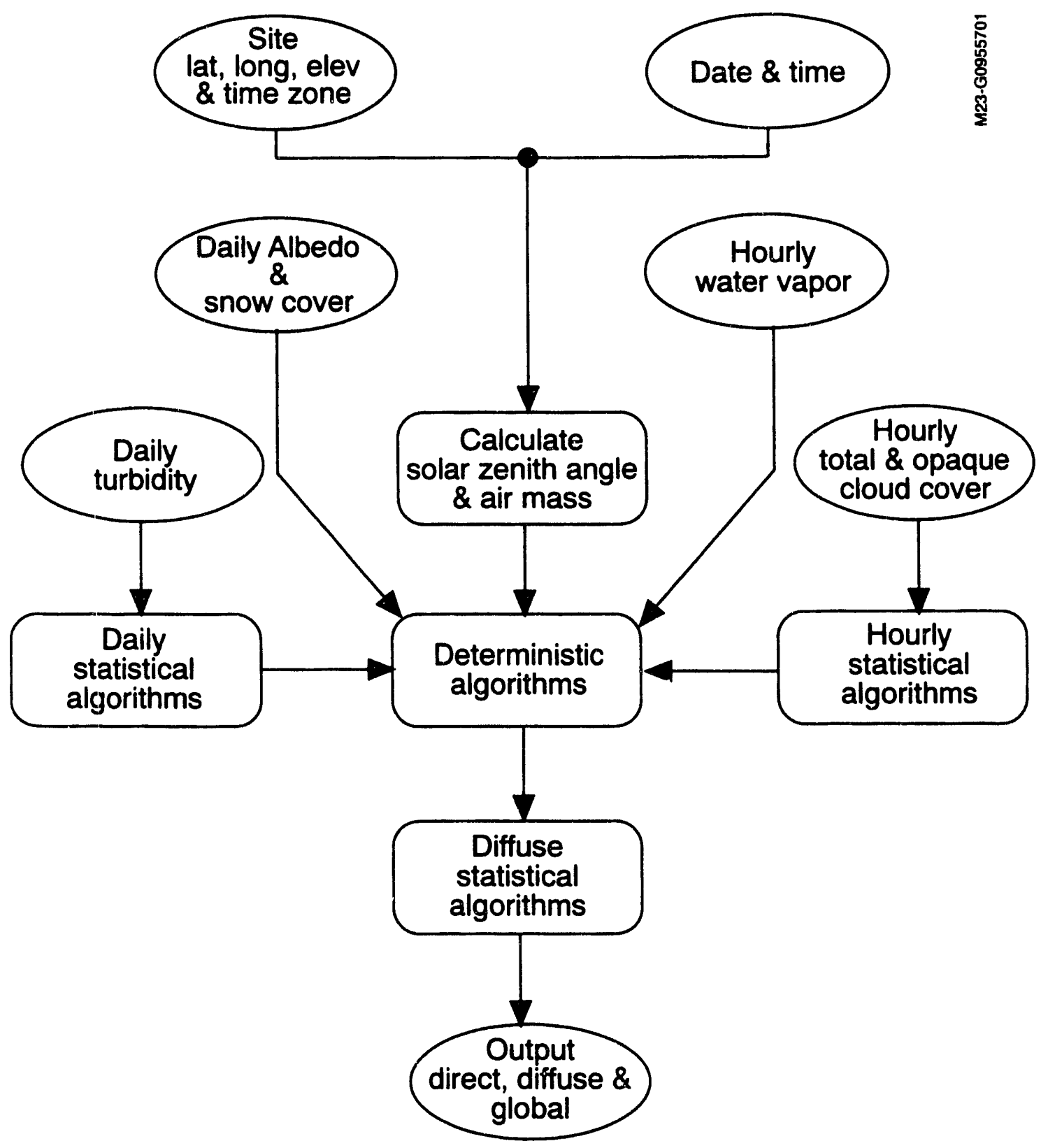

Figure B-2. Block diagram of the meteorological-statistical (METSTAT) model developed for estimating solar radiation from meteorological parameters 
Step 4: The time series plots of CCFs for each instrument were visually examined to look for discontinuities, such as that shown in Figure B-3. The station records for Fresno, California, indicated that an instrument change had occurred on February 5, 1963. These results, however, indicate that the instruments were actually changed on about October 22, 1962 (the CCFs in 1963 agree with those after October 22 in 1962). Many instances of unrecorded instrument or calibration factor changes were found. These "apparent" instrument change dates were then used to initiate new calculations and Step 3 was repeated.

Step 5: Once serial plots free of significant discontinuities were obtained, a linear least squares fit to the daily average CCFs for each instrument was obtained (see Figure B-4). The slope of the line fit to the data was used to determine the average daily rate of change of the pyranometer sensitivity during the entire period of its use at that station. The daily rate of change was used to remove the drift from all of the hourly CCFs.

Step 6: The drift-corrected hourly CCFs for each instrument were binned, i.e., placed in $10^{\circ}$-by$20^{\circ}$ zenith angle-azimuth angle cells. The number (count), mean, and standard deviation of the CCFs in each $10^{\circ}$-by- $20^{\circ}$ cell was calculated and used to form matrices such as those shown in Figure B-4 for Santa Maria, California (corresponds to the data in Figure B-5).

Step 7: The valid (not missing) CCFs for each $10^{\circ}$ zenith angle range were averaged to obtain a vector of correction factors $\left(\mathrm{CCF}_{\mathrm{vec}}\right)$, indicating the variation of the pyranometer sensitivity with zenith angle. A weighted (according to the cosine of the zenith angle) average of the drift-corrected hourly CCFs also was calculated to obtain a calibration correction factor for use under iso-

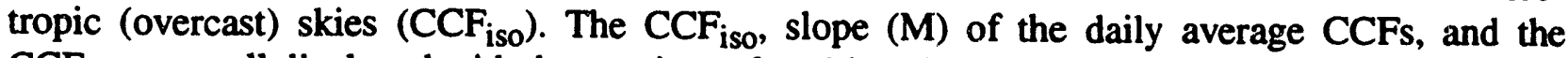
$\mathrm{CCF}_{\text {vec }}$ were all displayed with the matrices of zenith-azimuth cell data, as shown in Figure B-5.

Step 8: The information shown in Figure B-5 was developed for each pyranometer used at each of the 56 Primary stations in the NSRDB. This information was examined to select from several options for effecting calibration corrections. The vector and the matrices were examined to determine if sufficient data of adequate quality had been found to accurately define the pyranometer angular response characteristics. For the example shown in Figure B-5, the count of hourly CCFs in each cell and the standard deviation of the values in each cell indicate that the response characteristics were well defined by a large data sample. For many instruments, this was not the case. Either the period of use was too short or the weather was too cloudy to form an adequate set of data. In these instances, the $\mathrm{CCF}_{\mathrm{iso}}$ was used to correct all data. For other instruments, the data set was adequate to define the zenith angle response $\left(\mathrm{CCF}_{\mathrm{vec}}\right)$ but not the azimuth angle response. In a few rare instances, the data were not adequate to define even the $\mathrm{CCF}_{\mathrm{iso}}$, and no corrections were made.

Once the quality of the information was determined, a decision was made regarding the need to correct the data. If the CCFs appeared to fall within or close to the optimum uncertainty established for global horizontal measurements $( \pm 5 \%)$, no corrections were made. If the angular response characteristics were determined to be acceptable, but the needed corrections exceeded the $\pm 5 \%$ limit during any time that the instrument was in use, then the $\mathrm{CCF}_{\text {iso, }}$, adjusted for the daily drift of the instrument response, was imposed. In Figure B-5, we note a large zenith angle change ( $10 \%$ from $15^{\circ}$ to $\left.75^{\circ}\right)$ but very little azimuth variation in response and a large $(14.5 \%)$ drift (see Figure B-4) during the three years of use. Therefore, the $\mathrm{CCF}_{\mathrm{vec}}$, adjusted for daily 


\section{0.ve}
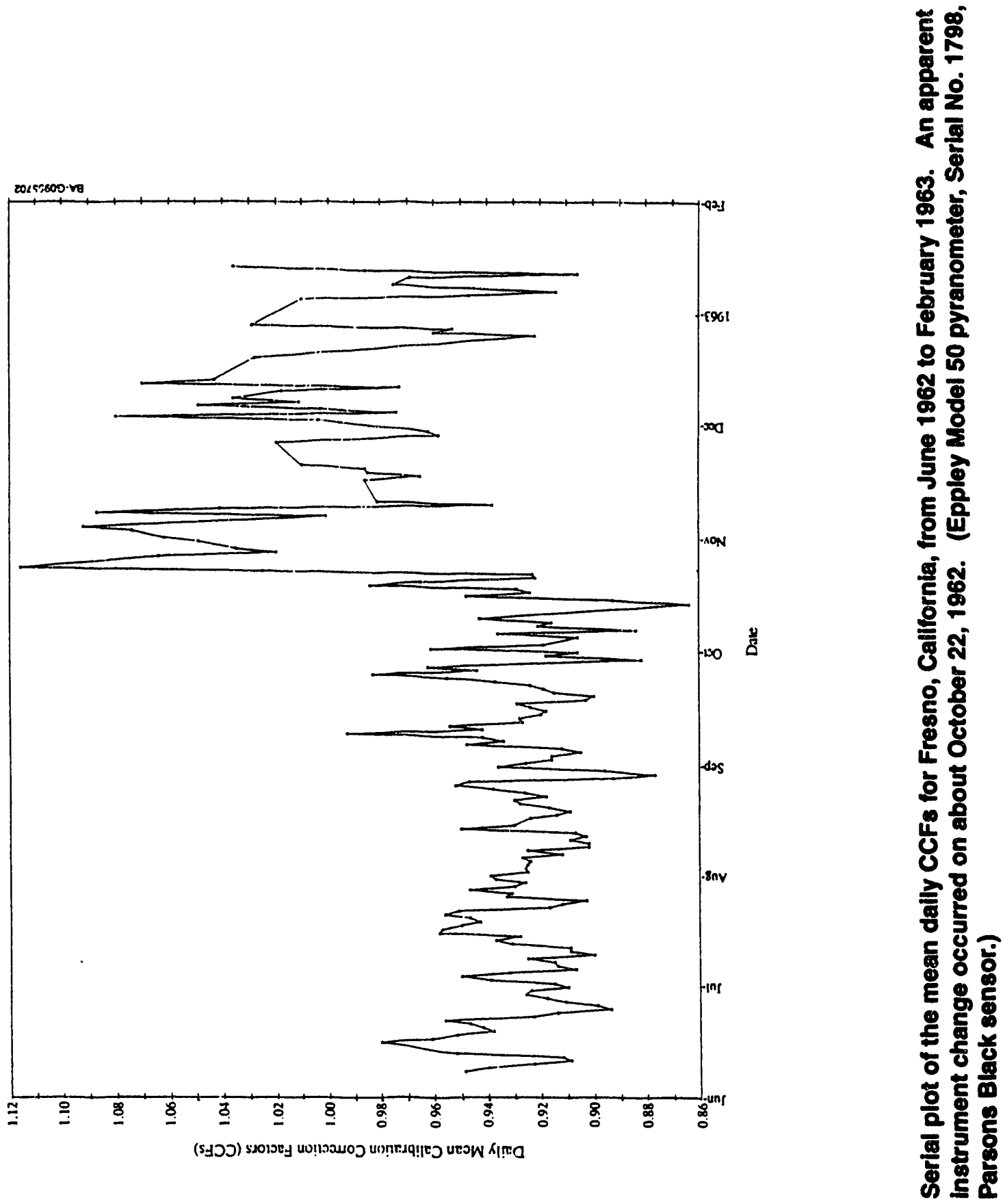

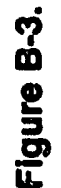




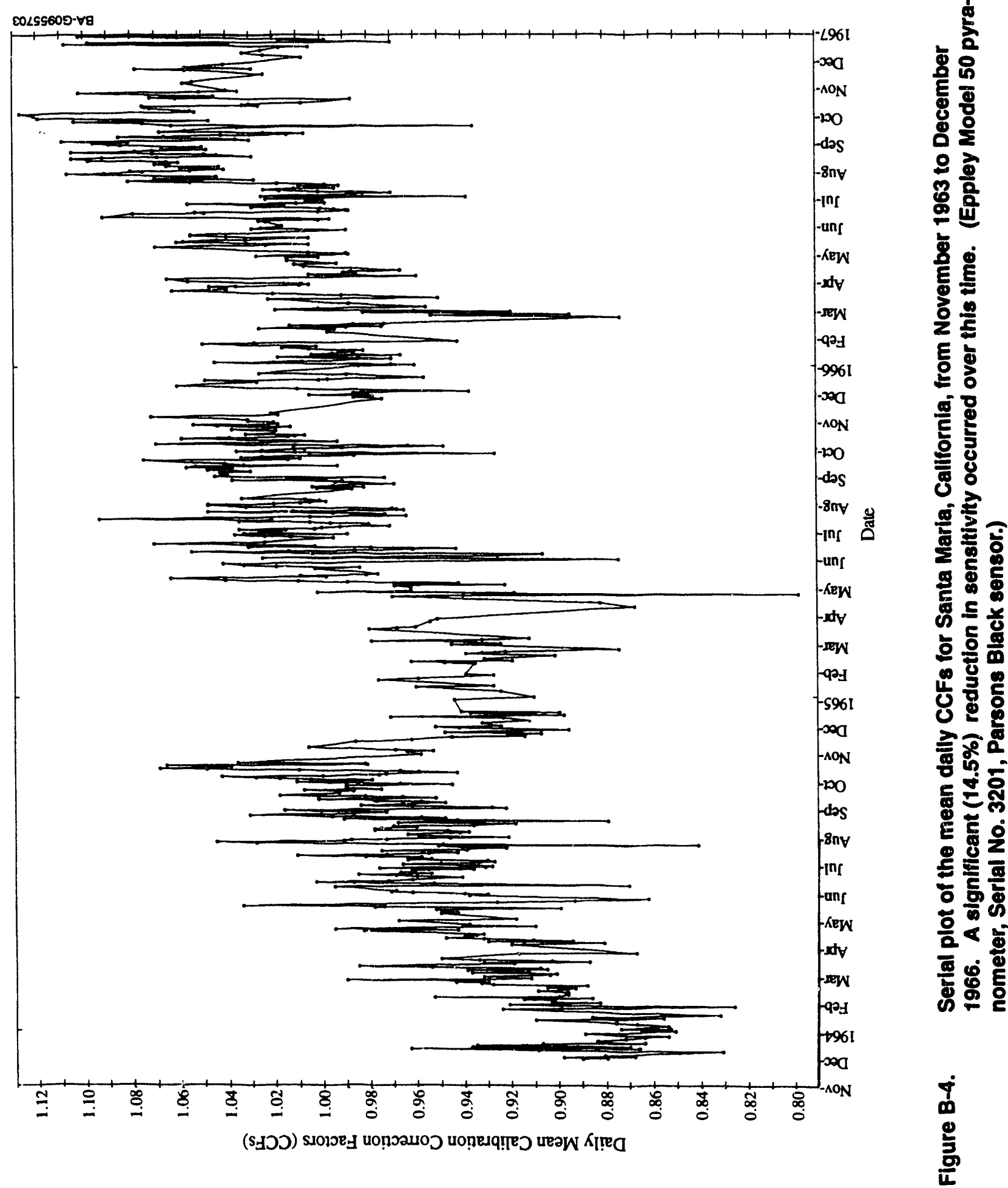




$$
\text { 8 }
$$

$\sum_{\frac{1}{2}}^{\infty}$

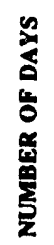

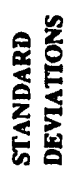

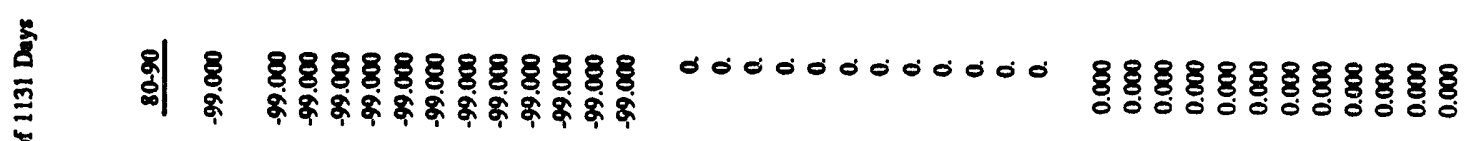

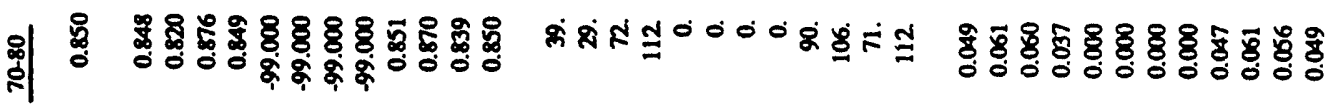

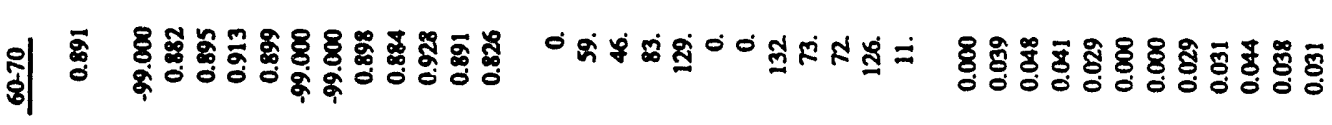

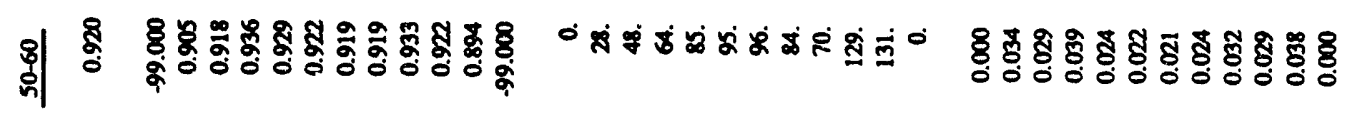

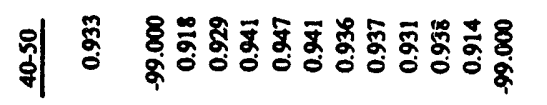

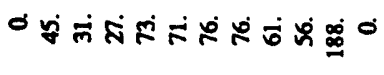

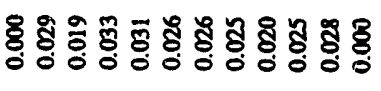

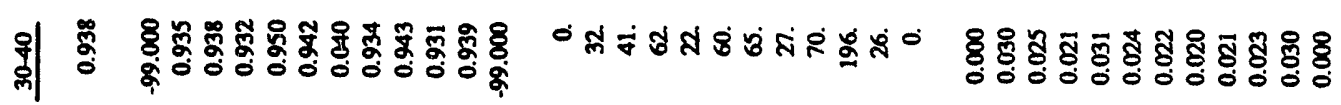

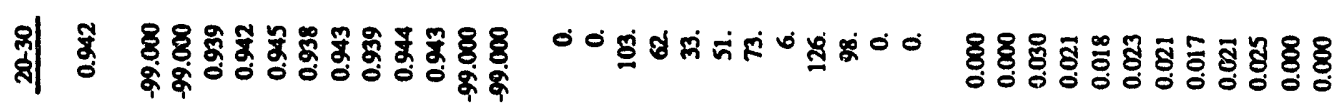

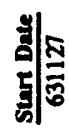

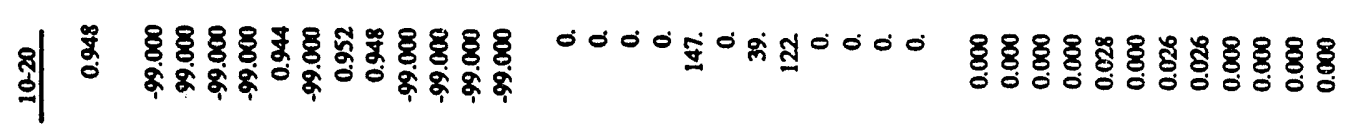
이 \&్ そ.

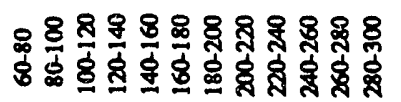
ग8ిषV qunषukv

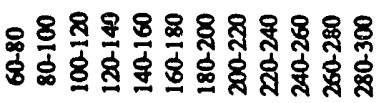
ग8ిay yगnسयद

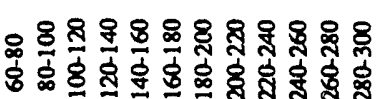

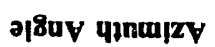


drift, was used to correct the data for these years. For some instruments, the matrix of correction factors $\left(\mathrm{CCF}_{\text {mat }}\right)$ was selected.

\section{Application of the Calibration Correction Factors}

Some of the empty cells (shown as -99.000 in Figure B-5) in the vectors and matrices were empty because the sun never occupies that region of the sky at that latitude. The cells for zenith angles from $80^{\circ}$ to $90^{\circ}$ were always empty because the algorithm excluded data in this range (Step 2). Other cells might be empty just because nu cloudless hours ever occurred when the sun was in that region. Therefore, in order to ensure the presence of a correction factor whenever needed, all of the cells in the vectors and matrices were filled through processes of extrapolation, interpolation, or w'eighted averaging of surrounding cells.

In order to simplify the computer application of the algorithm, an isotropic $\mathrm{CCF}_{\mathrm{iso}}$, a daily drift $(\mathrm{M})$, and a $\mathrm{CCF}_{\text {mat }}$ were always employed. When no calibration correction was to be made, the $\mathrm{CCF}_{\text {iso }}, \mathrm{M}$, and all of the cells in $\mathrm{CCF}_{\text {mat }}$ were set to 1.0. When only the isotropic correction was to be made, all of the cells in $\mathrm{CCF}_{\text {mat }}$ were set to the $\mathrm{CCF}_{\text {iso }}$ value. When a zenith angle correction was called for (with no azimuth angle correction), each column of the matrix, $\mathrm{CCF}_{\text {mat }}$, was filled with the corresponding $\mathrm{CCF}_{\text {vec }}$ value. And, of course, when both zenith and azimuth angle corrections were to be made, the original $\mathrm{CCF}_{\text {mat }}$ was employed.

Following the required modification (if any) of the $\mathrm{CCF}_{\text {iso }}, \mathrm{M}$, and $\mathrm{CCF}_{\text {mat }}$ correction factors, the calibration correction factor to be applied to each hourly datum $\left(\mathrm{CCF}_{\text {app }}\right)$ was determined from the equation,

$$
\mathrm{CCF}_{\mathrm{app}}=\mathrm{CCF}_{\text {mat }}\left[1-(\mathrm{OPQ} / 10)+\mathrm{CCF}_{\text {iso }}(\mathrm{OrQ} / 10)\right]+\mathrm{N}_{\text {days }} \mathrm{M}
$$

where

$$
\text { OPQ is the opaque sky cover for the hour }
$$

$$
N_{\text {days }} \text { is the } \mathbf{n} \text {.mber of days since the instrument had been placed in use. }
$$

Therefore, under skies free of opaque clouds $(\mathrm{OPQ}=0), \mathrm{CCF}_{\mathrm{app}}$ was determined only by the values found in $\mathrm{CCF}_{\text {mat }}$, adjusted fr - daily drift. Under overcast skies $(\mathrm{OPQ}=10)$, only the $C C F_{\text {iso }}$ value was applied. Under partiy cloudy skies, a combination (weighted by opaque sky cover) of $\mathrm{CCF}_{\text {mat }}$ and $\mathrm{CCF}_{\text {iso }}$ values, plus drift, determined $\mathrm{CCF}_{\text {app }}$.

In the presence of translucent clouds (e.g., cirrus), the correction would be in error because the translucent clouds c. uld affect both the direct beam and diffuse sky radiation. No attempt was made to account for this because the efiects were relatively small and of uncertain magnitude. The corrections made under partly cloudy skies should also be considered as estimates because of the random effects that can be attributed to the position of the clouds in the sky. 


\section{SYNCAL Improvements over the SYVCSN SOLMET Procedure}

The synthetic calibration (SYNCAL) procedure developed for the National Solar Radiation Data Base (NSRDB) represents an improvement over the SYI/CSN procedure used for the SOLMET/ ERSATZ data base. The improved featires of SYNCAL are summarized below:

- $\quad$ An improved model (METSTAT) using improved input data (aerosol optical depth and precipitable water) was used to calculate global horizontal solar radiation under clear skies.

- All clear-sky hours with zenith angles less than $80^{\circ}$ were employed. This significantly increased the quantity of data involved in the calculations.

- The daily average CCFs were serially plotted for the entire period of record to detect any anomalies, drifts, or instrument changes and to avoid adding SYNCAL artifacts to the data.

- The drift-corrected hourly CCFs were binned in $10^{\circ}$ - by- $20^{\circ}$ zenith-azimuth cells to allow full characterization of the pyranometers when adequate measured data were available.

- The use of average CCFs that define pyranometer response characteristics (based on the instrument's entire period of use), has served to avoid "corrections" that would eliminate or override the real effects of changes in atmospheric conditions (aerosol optical depth and precipitable water).

\section{References}

Baker, D.G., Skaggs, R.H., and Ruschy, D.L. (1991). "Snow Depth Required to Mask the Underlying Surface," Journal of Applied Meteorology, Vol. 30, pp. 387-392.

Baker, D.G., Ruschy, D.L., and Wall, D.B. (1990). "The Albedo Decay of Prairie Snows," Journal of Applied Meteorology, Vol. 29, pp. 179-187.

Bird, R.E. and Hulstrom, R.L. (1981). A Simplified Clear Sky Model for Direct and Diffuse Insolation on Horizontal Surfaces. SERJ/TR-642, Solar Energy Research Institute, Golden, CO.

Iqbal, M. 1983). An Introduction to Solar Radiation. Academic Press, New York, Chap. 7, pp. 169-213.

SOLMET. (1979). Vol. 2, Final Report-Hourly Solar Radiation: Surface Meteorological Observations. TD-9724, National Climatic Data Center, Asheville, NC.

Valko, P. (1980). "Some Empirical Properties of Solar Radiation and Related Parameters," DOE/ ER-0084, IEA Task IV, in An Introduction to Meteorological Measurements and Data Handling for Solar Energy Applications, U.S. Department of Energy, Washington, DC. 

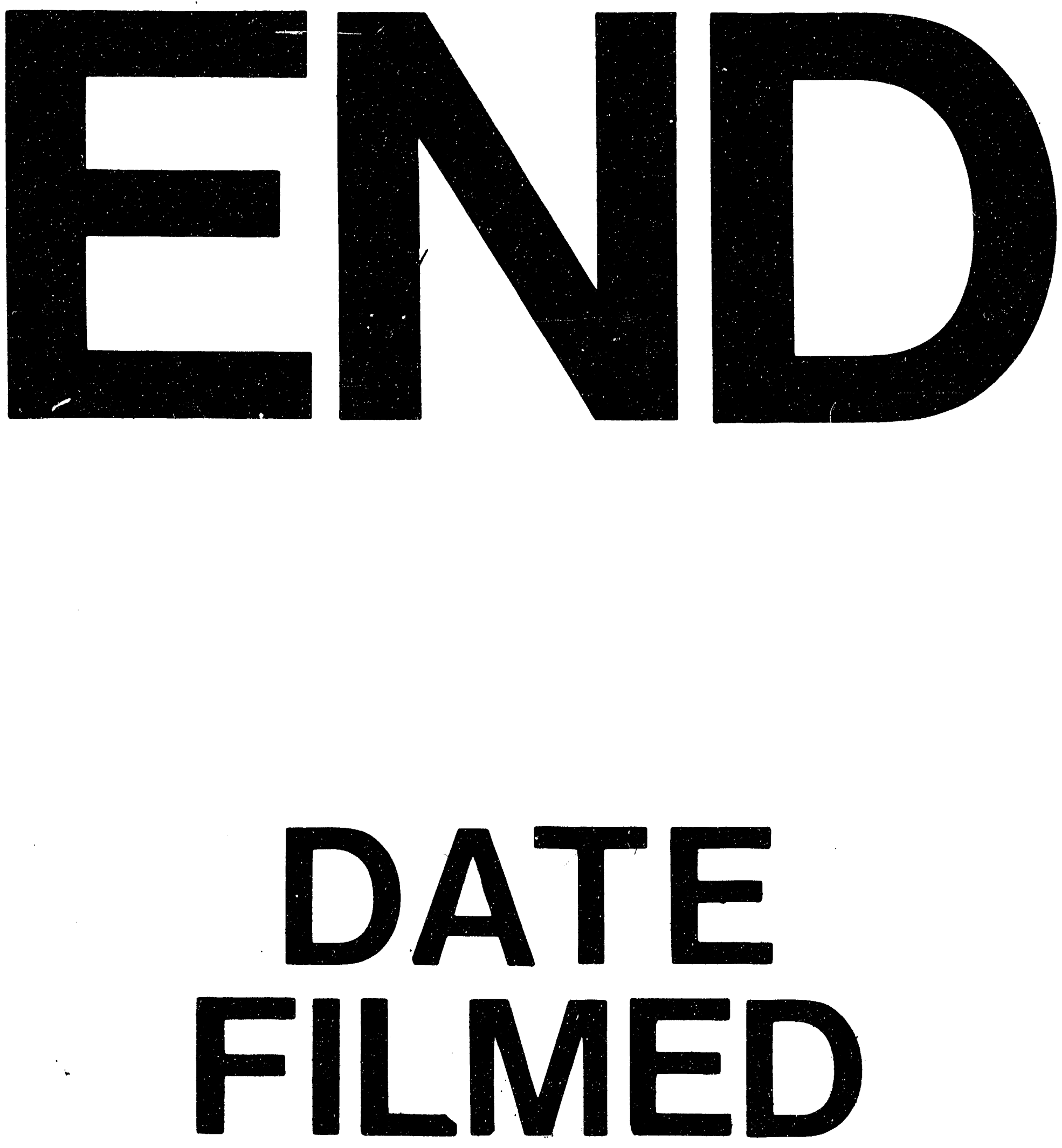

7)

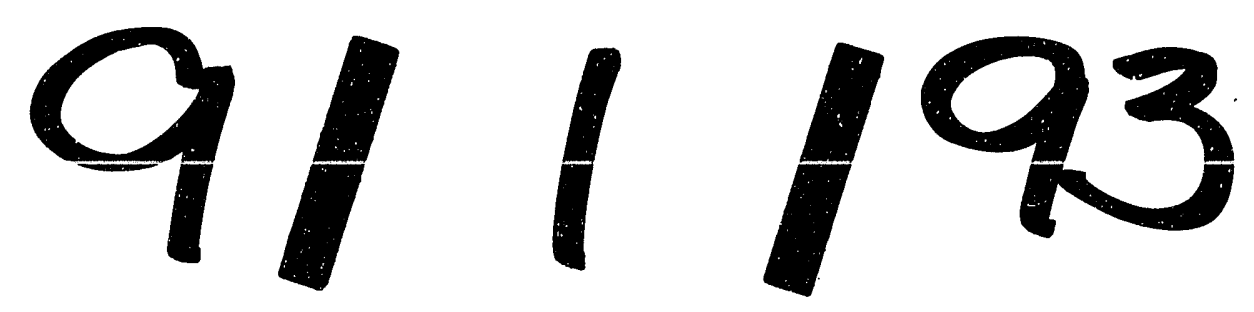




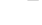

